\title{
EL MODELO DE CRIMINALIDAD MEDIEVAL Y SU MODERNIZACIÓN. LÍMITES INTERPRETATIVOS Y METODOLÓGICOS*
}

\author{
Iñaki Bazán Díaz** \\ (UPV/EHU)
}

\section{RESUMEN}

Este artículo está estructurado en tres partes. En la primera se expone el modelo de criminalidad medieval que las investigaciones han centrado en la conducta violenta y en el delito de homicidio como principal protagonista. En la segunda parte se explica el argumento del proceso de modernización de la criminalidad medieval, según el cual al final de la Edad Media se iniciaría un proceso de disminución multisecular de las tasas de delitos de sangre. En la tercera y última parte, se reflexiona sobre los límites interpretativos y metodológicos de este modelo de criminalidad medieval centrado en la violencia y su evolución posterior. Palabras clave: criminalidad, violencia, homicidio, Edad Media, evolución de la criminalidad.

\section{THE MEDIEVAL CRIME MODEL AND ITS MODERNIZATION.} INTERPRETIVE AND METHODOLOGICAL LIMITS

\section{Abstract}

The present paper is divided into three sections. The first one deals with that model of medieval criminality in which research has focused on violent conduct and on the crime of homicide as a main issue. The second section accounts for the modernization process of medieval criminality. According to it, a multisecular decline in blood crimes rates would be started in the late Middle Ages. The third and final section offers some reflections on the interpretative and methodological boundaries of this medieval criminality model focused on violence and its subsequent evolution.

KEYwORDs: criminality, violence, homicide, Middle Ages, evolution of criminality. 


\section{INTRODUCCIÓN}

Desde los años 60 del siglo xx se fue construyendo, a partir del análisis de las fuentes seriales, un modelo de criminalidad medieval centrado en la primacía de la violencia homicida y que a lo largo de la Edad Moderna fue retrocediendo paulatinamente hasta alcanzar su mínimo histórico en los albores de la contemporaneidad, al mismo tiempo que, según la hipótesis normanda, era remplazada por los delitos contra el patrimonio. Si bien este segundo corolario de la evolución multisecular o de modernización de la criminalidad medieval en la actualidad no es admitido por la historiografía, sí se han seguido realizando investigaciones para entender las razones de ese declinar de la violencia homicida más allá de los cuestionables datos estadísticos. En consecuencia, es mucha la bibliografía que en las últimas décadas ha surgido sobre el particular, como bien ha señalado J. Carter Wood, lo que dificulta resumir de manera eficiente sus logros ${ }^{1}$. Por ello, este trabajo tan sólo pretende ser una aproximación, seguramente incompleta, a algunos de los límites interpretativos y metodológicos del modelo de criminalidad medieval y de su evolución histórica. Por otro lado, las síntesis interpretativas realizadas sobre ese declinar multisecular de la violencia medieval, como la del sociólogo Manuel Eisner ${ }^{2}$ o las de los historiadores Pieter Spirenburg, Robert Muchembled o Xavier Rousseaux, entre otros muchos, han utilizado en sus análisis comparativos muy marginalmente investigaciones referidas al ámbito hispano, por ello en este trabajo se incidirá en mayor medida en ellas ${ }^{3}$.

Para abordar este objetivo aproximativo este estudio ha sido estructurado en tres partes. En la primera se expondrá el modelo de criminalidad medieval que las investigaciones han centrado en la conducta violenta y en el delito de homicidio como principal protagonista. En la segunda parte se explicará el argumento del

* Este trabajo se enmarca en el proyecto de investigación titulado De la Lucha de Bandos a la hidalguia universal: transformaciones sociales, politicas e ideológicas en el País Vasco (siglos XIV y XV), financiado por el MINECO y con el código HAR2017-83980-P. Así como en el grupo de investigación consolidado del Gobierno vasco Sociedad, poder y cultura (siglos XIV-XVIII), código IT-896-16. Igualmente, este artículo tendrá una mirada especial a la historiografía hispana, a la que no se recurre tradicionalmente en los balances historiográficos realizados por especialistas europeos.

** ORCID ID: http://orcid.org/0000-0003-3407-6233. E-mail: i.bazan@ehu.eus.

1 «Criminal violence in modern Britain». History Compass, 4-1 (2006), p. 78. Un ejemplo de la abundante bibliografía que se ha generado en las dos últimas décadas sobre la criminalidad medieval es la completa, extensa y bien informada síntesis realizada por F. SEGURA URRA, «Raíces historiográficas y actualidad de la historia de la justicia y el crimen en la Baja Edad Media». Anuario de Historia del Derecho Español, n. ${ }^{\circ} 73$ (2003), pp. 577-678.

2 «Modernization, self-control and lethal violence. The long-term dynamics of European homicide, rates in theoretical perspective». The British Journal of Criminology, n. ${ }^{\circ} 41$ (2001), pp. 618638; "Long-tern historical trends in violent crime». Crime and Justice. A Review of Research, n. ${ }^{\circ} 30$ (2003), pp. 83-142.

${ }_{3}$ Para una síntesis sobre la historiografía española de las últimas dos décadas sobre la criminalidad medieval vid. F. Segura Urra, «La historia de la delincuencia en la España medieval (1998-2008)». Medievalismo, n. ${ }^{\circ} 18$ (2008), pp. 273-338. 
proceso de modernización de la criminalidad medieval, según el cual al final de la Edad Media se iniciaría un proceso de disminución multisecular de las tasas de delitos de sangre. En la tercera y última parte, se reflexionará sobre los límites interpretativos y metodológicos de este modelo de criminalidad medieval centrado en la violencia y su evolución posterior.

\section{EL MODELO DE CRIMINALIDAD MEDIEVAL}

Los investigadores han comprobado que el comportamiento delictivo que predominaba en la limitada estadística criminal de la sociedad medieval era el de violencia de sangre. En este sentido se pueden mencionar los estudios clásicos realizados por Jacques Chiffoleau, Claude Gauvard, Robert Muchembled, James B. Given o Barbara A. Hanawalt. Por ejemplo, la profesora de la Universidad de la Sorbona Claude Gauvard, en su aclamada tesis de estado ${ }^{4}$, obtuvo las siguientes conclusiones a través del análisis de unas 7500 cartas de perdón concedidas por la Cancillería real francesa durante el período 1380-1425: el 56\% de los delitos recogidos en ellas eran homicidios y tan sólo el 16\% robos; y el 99\% de los causantes de una muerte eran varones, así como el 79\% de las víctimas. En consecuencia, Gauvard señalaba que el delito violento "peut être considéré comme le grande criminalité médiévale»" ${ }^{5}$. En esta estadística también se ponía de manifiesto uno de los caballos de batalla de la historiografía a la hora de interpretar la evolución multisecular del modelo de criminalidad medieval, o de Antiguo Régimen, como lo denominó Jacques Chiffoleau: menor presencia de los atentados contra la propiedad frente a delitos de sangre; relación que se invertiría a partir de los siglos XVIII/ $\mathrm{XIX}^{6}$.

La violencia y los crímenes de sangre respondían a una etiología muy variada, ligada a situaciones de miseria económica, a conflictos sociales derivados de situaciones de sometimiento, a persecuciones religiosas, a guerras entre reinos o entre señores y linajes o a luchas de poder en el mundo urbano. Pero, si hubo una causa primordial generadora de enfrentamientos violentos de consecuencias fatales en la sociedad medieval, ésa fue el honor.

El honor era una expresión de un sistema de valores compartido, un fermento conformador de la mentalidad que orientaba los comportamientos y las acti-

4 "De grace especial». Crime, état et société en France à la fin du Moyen Âge. Paris, Publications de la Sorbonne, 1991, 2 vols. Recibió, entre otros, los siguientes premios: Premio Malesherbes de la «Association pour l'Histoire de la Justice» y Premio Gobert de la «Académie des Inscriptions et Belles-Lettres».

5 "De grace especial», vol. I, pp. 241-243.

${ }^{6}$ Jacques Chiffoleau señaló al respecto: «Dès le debut du xive siècle sa criminalité -qui est faite surtout de violence- participe pleinement de cette "criminalité d'Ancien Régime" où les coups, les rixes, les injures et les homicides l'emporten toujours nettement sur les vols et les atteintes à la propiété»; vid. "La violence au quotidien. Avignon au XIve siècle d'après les registres de la Cour temporelle». Mélanges de l'Ecole Française de Rome. Moyen-Âge, Temps modernes, t. 92 , n. ${ }^{\circ} 2$ (1980), p. 344. 
tudes, y un principio organizador de las relaciones sociales. En este sentido, sobre su base se asentaba la buena la reputación de los individuos en la comunidad. Suponía un patrimonio moral que les otorgaba un crédito o capital simbólico ${ }^{7}$, que ponían en juego en sus relaciones sociales y que les permite participar de las redes de solidaridad y sociabilidad ${ }^{8}$. Pero cuando se desencadenaba una afrenta o injuria a ese honor era necesario su reparación para recuperar la posición social previa y para ello se recurría a la violencia. Se trataba de una violencia legítima, inexcusable y que contaba con la comprensión social y judicial, como en el caso del uxoricidio honoris causa como consecuencia de la relación adúltera de la esposa ${ }^{9}$. En este sentido se puede explicar la abrumadora presencia de varones implicados en casos de violencia frente a mujeres, ya que a los hombres de la casa les correspondía defender y restaurar el honor personal y familiar mancillado, el prestigio público y la valía social. Si se cedía a la ofensa, ya fuera una injuria, un adulterio, una amenaza..., la infamia y la deshonra (humillación pública y rechazo social) se cerniría sobre esa persona, al igual que sobre su familia y allegados de diversa índole. Por eso ellos también reaccionaban como si hubieran sido asimismo ofendidos. Las relaciones familiares, vecinales, clientelares, gremiales o parroquiales generaban unos lazos de sociabilidad que obligaban a salir en auxilio de su allegado, participando en estas formas de violencia institucionalizada ${ }^{10}$.

Esta violencia no era patológica, sino que formaba parte de la vida cotidiana como una manifestación de las tensiones en el seno de la comunidad y como un mecanismo de resolución de conflictos. En consecuencia, a través de esta gestión privada del conflicto se buscaba un desagravio por el daño sufrido y restablecer el equilibrio social roto. No obstante, no podía ejercerse en plena libertad, debía ajustarse a una serie de reglas para evitar que la comunidad terminara destruida en un ciclo de acción-reacción ${ }^{11}$. Este mecanismo de gestión privada del conflicto surgió, según señala Barbara A. Hanawalt, de la minusvaloración de la vida en términos demográficos y de la incapacidad del sistema legal para resolver los enfrentamien-

7 P. Bourdieu, Razones prácticas sobre la teoría de la acción. Barcelona, 1997 (1994), pp. 179-186.

${ }^{8}$ C. Maiza, «La definición del concepto del honor. Su identidad como objeto de investigación histórica». Espacio, Tiempo y Forma. Historia Moderna, n. ${ }^{\circ} 8$ (1995), pp. 191-209.

${ }^{9}$ Los familiares de ella, los tribunales de la Corona y la sociedad comprendían y perdonaban al marido homicida por entender su acción como un castigo por el comportamiento deshonesto cometido y una forma de superar la afrenta al honor familiar. Sobre esta cuestión, por ejemplo, I. BAZÁN, «El pecado y el delito de adulterio en la Castilla medieval. Transgresiones del modelo de sexualidad conyugal y su castigo", en Arte y sexualidad en los siglos del románico: imágenes y contextos. Aguilar de Campoo, Fundación Santa María la Real del Patrimonio Histórico, 2018, pp. 11-51.

${ }^{10} \mathrm{C}$. Gauvard, «Violence citadine et réseaux de solidarité. L'example français au XIV et xve siècles». Annales ESC, n. ${ }^{\circ} 48$ (1993), pp. 1119-1121.

${ }^{11}$ C. Gauvard analiza de manera extensa la venganza como una de las causas generadoras de homicidios en la Francia medieval, «De grace especial», vol. II, cap. 17, pp. 753-788. Una obra colectiva actual sobre la temática es la dirigida por C. GAUvard \& A. Zorzi, La vengance en Europe, XII ${ }^{e}$-XVIII siècle. Paris, Publications de la Sorbonne, 2015. 
tos entre partes de una manera rápida y efectiva ${ }^{12}$. A partir del siglo xIII, y hasta el siglo xv, la justicia real buscó consolidarse y asentarse en el territorio, como en el caso de la Corona de Castilla, a través de los alcaldes ordinarios (jueces de primera instancia) y de los corregidores (delegados regios con atribuciones judiciales), pero incluso al final del período se mantuvo el recurso al ejercicio de la venganza, aunque para ello se requería la autorización de los tribunales tras juzgarse la causa y pronunciarse la sentencia. En otras palabras, al finalizar la Edad Media el sistema de los tribunales de justicia, con la imposición de penas para sancionar a quienes transgredían la paz y para reparar el honor y el daño a las víctimas, no había conseguido erradicar del todo el sistema vindicatorio privado ${ }^{13}$. En este sentido, Valérie Toureille ha señalado que la «société médievale n’a pas délégué à l'autorité publique la totalité de ser pouvoirs en matière de criminalités ${ }^{14}$.

Jacques Chiffoleau introdujo otro argumento, además de la defensa del honor, para explicar la sobrerrepresentación de la violencia en la sociedad medieval: el desarrollo del mundo urbano acontecido a partir del siglo XIV y que traería consigo el desarraigo de las solidaridades tradicionales, consanguíneas y territoriales, de quienes se asentaron en las ciudades (3/4 de la población de Avignon era inmigrante, por ejemplo). No obstante, buena parte de los recién llegados sí conseguirían establecer nuevos lazos de sociabilidad por pertenecer a un gremio, a una cofradía, a una parroquia o a un barrio, pero otros muchos no, como los jóvenes domésticos, los jornaleros, los marginados ${ }^{15}$..., incapaces de insertarse económica ni culturalmente en una sociedad urbana en plena transformación, y que conformarían un grupo especialmente violento. Por otro lado, esta nueva sociedad urbana también generaba tensiones interpersonales causadas por una vida cotidiana en la que se entremezclaban y rozaban muchas almas en un espacio cercado ${ }^{16}$.

Para Robert Muchembled cabría añadir un tercer argumento: el de los jóvenes varones célibes que desarrollaban rituales de integración social y de remplazo generacional a partir de la puesta en valor de la ética de la virilidad. Durante la larga espera para acceder al matrimonio, para heredar el título o el negocio paterno, para adquirir la condición de adulto pleno con todos los derechos (políticos, por ejemplo), rivalizaban y competían entre sí violentamente para demostrar que estaban en condiciones de formar una familia y de reproducirse, asegurando la continuidad del linaje (disputas por el amor de una joven, porque las uniones seguían criterios de

12 Crime and conflict in English communities, 1300-1348. Cambridge, Harvard University Press, 1979, pp. 173-177.

13 I. BAZÁN, «La pervivencia de la venganza privada junto al ius puniendi real en los casos de contumacia, piratería y uxoricidio honoris causa en la Corona de Castilla (siglos XIII al Xv)», en C. Gauvard \& A. Zorzi (dirs.), La vengance en Europe, pp. 209-226.

${ }_{14}$ Crime et châtiment au Moyen Âge, ve-Xve siècle. Paris, Seuil, 2013, p. 92.

${ }^{15}$ En el caso de la Corona de Castilla uno de los investigadores que ha incidido en la relación existente entre marginación y criminalidad ha sido R. CóRDOBA DE LA Llave, «Marginación social y criminalización de las conductas». Medievalismo: Boletín de la Sociedad Española de Estudios Medievales, n. ${ }^{\circ}$ 13-14 (2004), pp. 293-322.

16 «La violence au quotidien», pp. 355-357 y 366-367. 
endogamia social y geográfica), de defender su posición social y de hacerse con un hueco en la comunidad. Se trataría de un comportamiento violento jaleado por los adultos como vía de integración y de alcanzar la categoría de hombres completos ${ }^{17}$. Se puede afirmar que la identidad masculina se construía a través de la violencia. Además, los jóvenes se educaban en y con violencia, un ejemplo paradigmático lo constituyen los hijos de los nobles que eran adiestrados en una cultura guerrera, pero también eran reprendidos los aprendices por sus maestros. La reprensión con una finalidad correctora se trasladaba también al ámbito doméstico, padeciéndola hijos, criados y esposas por parte del varón que ostentaba la patria o marital potestad ${ }^{18}$.

La presencia del varón era abrumadora en casi todas las categorías de comportamiento violento ${ }^{19}$, con algunas excepciones, como en los casos de aborto, de infanticidio ${ }^{20}$ o de envenenamiento ${ }^{21}$ que tenían por protagonista a una mujer; además de en los delitos relacionados con la moral, como la prostitución, el adulterio o la brujería. No obstante, también habría que tener en presente, y no minusvalorar, la participación de las mujeres en acciones violentas, ya fueran como instigadoras o en apoyo de sus familias en la defensa del honor o participando en revueltas sociales. No en vano ellas mismas estaban inmersas en la cultura de la violencia. Aunque también desempeñaron un papel importante como mediadoras y pacificadoras en momentos de tensión ${ }^{22}$. Pero ¿̨por qué ese menor comportamiento violento y

17 «Les jeunes, les jeux et la violence en Artois au xve siècle», en P. Ariès \& J.-C. MarGolin (eds.), Les jeux à la Renaissance, Paris, Vrin, 1982, pp. 563-579. La tesis sobre la incidencia de los varones jóvenes en las tasas de violencia y su evolución multisecular la desarrolla en Una historia de la violencia. Del final de la Edad Media a la actualidad. Madrid, Paidós, 2010 (2008). Véase para el caso hispano a M. ${ }^{a}$ del C. García Herrero, «Vulnerables y temidos: los varones jóvenes como grupo de riesgo para el pecado y el delito en la Baja Edad Media», en M. ${ }^{a}$ del C. García Herrero, Los jóvenes en la Baja Edad Media. Estudios y testimonios, Zaragoza, Institución Fernando el Católico, 2018, pp. 113-148.

${ }_{18}$ M. ${ }^{a}$ del C. García Herrero, «La marital corrección. Un tipo de violencia aceptado en la Baja Edad Media». Clio \& Crimen. Revista del Centro de Historia del Crimen de Durango, n. ${ }^{\circ} 5$ (2008), pp. 39-71.

${ }_{19}$ Los porcentajes de varones culpables de homicidios se sitúan en torno al 90\% según atestiguan los trabajos, por ejemplo, de Claude Gauvard para Francia ("De grace especial») y de James B. Given para Inglaterra (Society and homicide in Thirteenth century England. Stanford, Stanford University Press, 1977). Un estudio sobre la delincuencia femenina en la Corona de Castilla es el de J.M. Mendoza, «Sobre la delincuencia femenina en Castilla a fines de la Edad Media», en R. CórDOBA DE LA LlaVE (coord.), Mujer, marginación y violencia entre la Edad Media y los tiempos modernos, Córdoba, Universidad de Córdoba, 2006, pp. 75-126.

${ }^{20}$ Y.-B. Brissaud, «L'infanticide à la fin du Moyen Âge, ses motivations psychologiques et sa répression». Revue Historique de Droit Français et Étranger, n. ${ }^{\circ} 95$ (1972), pp. 229-256; A. RodríGUez GonzÁlez, "El infanticidio en la España moderna: entre la realidad y el discurso jurídico y moral». Tiempos Modernos, 36 (2018/1), pp. 280-301.

${ }^{21}$ F. Collard, Le crime de poison au Moyen Âge. Paris, PUF, 2003.

22 R. Córdoba de la Llave, «El homicidio en Andalucía a fines de la Edad Media. Primera parte. Estudio». Clio \& Crimen. Revista del Centro de Historia del Crimen de Durango, n. ${ }^{\circ} 2$ (2005), p. 368; M. a del C. García Herrero, "Árbitras, arbitradoras y amigables componedoras en la Baja Edad Media aragonesa», en M. ${ }^{a}$ del C. García Herrero, Del nacer y el vivir. Fragmen- 
homicida en las mujeres? Algunos autores han considerado que podría deberse a una subrepresentación femenina en el registro criminal como consecuencia de un sesgo en los tribunales de justicia, que trasladarían la sanción al marido o al padre de la mujer condenada ${ }^{23}$, como ocurría en el Midi francés ${ }^{24}$; o porque se hubiera resuelto el conflicto de forma privada por cauces extrajudiciales, como en el caso de las cartas de perdón de cuernos otorgadas a las esposas adúlteras ${ }^{25}$. Pero quizás el argumento principal correspondería al control informal al que eran sometidas las mujeres para que no se apartaran del modelo de comportamiento virtuoso, por lo que sus movimientos fuera del espacio doméstico-familiar quedaban muy limitados ${ }^{26}$. Por ello diría Claude Gauvard que cuando una mujer entraba en el espacio público acrecentaba "ses chances de devenir criminelle ou victime»"

En resumen, a partir de los siglos XIII/XIV habría surgido un modelo de criminalidad que se caracterizaría por la preponderancia de crímenes relacionados con la violencia (homicidio, agresiones físicas, riñas, injurias...), en mayor medida que contra la propiedad. Este modelo violento se concretaría en los siguientes términos: por el recurso a la violencia como mecanismo de resolución de conflictos; por una concepción social no criminal de la violencia ligada a la cultura del honor y a la ética viril; por tener un componente emocional e impulsivo, sin premeditación; por ejercerse en público y colectivamente; por un predominio de la violencia homicida protagonizada por varones, especialmente jóvenes de entre 20 y 30 años en proceso de remplazo generacional; por existir un conocimiento previo entre la víctima y el agresor en el marco de la sociabilidad comunitaria (violencia de proximidad geográfica y socioprofesional); y por implicar en menor medida a la violencia intrafamiliar, más allá del castigo con fines correctores.

En efecto, en la Edad Media existió una cultura de la violencia con la finalidad de gestionar conflictos y tensiones, al punto de que en la inconsistente estadística criminal los delitos de sangre adquirieron una especial relevancia frente al resto. Otra cuestión diferente, y aquí surge el primer problema que plantea este modelo de criminalidad medieval, es si esa preponderancia de la violencia de sangre también preocupaba o generaba alarma social en mayor medida que el resto de delitos.

tos para una historia de la vida en la Baja Edad Media, Zaragoza, Institución Fernando el Católico, 2005, pp. 353-383.

${ }^{23} \mathrm{X}$. Rousseaux, «Historiographie du crime et de la justice criminelle dans l'espace français (1990-2005). Partie I: du Moyen-Âge à la fin de l'Ancien Régime». Crime, Histoire \& Sociétés / Crime, History \& Societies, vol. 10, n. ${ }^{\circ} 1$ (2006), párrafo 15, consultado el 30 de septiembre de 2016, http://chs.revues.org/203.

${ }^{24}$ B. Garnot, La justice en France de l'an mil à 1914. Paris, Nathan, 1993, p. 19.

${ }^{25}$ A modo de ejemplo, A. Viña Brito, «La "carta de perdón de cuernos" en la documentación notarial canaria del siglo XVI». Revista de Historia Canaria, 20 (2005), pp. 263-272.

${ }^{26}$ F. Sabaté, «Femmes et violencia dans la Catalogne du Xive siècle». Annales du Midi. Revue de la France méridionale, t. 106, n. ${ }^{\circ} 207$ (1994), pp. 277-316; I. BAZÁN, «Mujeres, delincuencia y justicia penal en la Europa medieval. Una aproximación interpretativa», en R. CóRDOBA (coord.), Mujer, marginación y violencia entre la Edad Media, pp. 29-74, en especial pp. 32-47.

27 «De grace especial», vol. 1, p. 326. 
Obviamente, la respuesta es no, porque, en primer lugar, ciertos comportamientos violentos estaban dentro del marco ético y legal como fórmula de resolución de conflictos, además de estar social y judicialmente tolerados ${ }^{28}$. Incluso en determinadas circunstancias si no se respondía con la fuerza se consideraba que era un signo de debilidad y generaba igualmente rechazo social. Y, en segundo lugar, porque había otros delitos, además del homicidio, considerados «atroces» por el derecho y la socie$\mathrm{dad}^{29}$, como la sodomía, la lesa majestad, la herejía, el rapto de doncella, el estupro, el sacrilegio... Muchos de ellos a la par que delitos también eran considerados pecados y se les asignaban penas infamantes, que en algunos casos continuaban post mortem. Por tanto, para acceder a la criminalidad de una sociedad como reflejo de su escala de valores y de sus normas de comportamiento es necesario dirigir la mirada tanto al crimen ordinario, en todas sus manifestaciones, como también al extraordinario o excepcional, porque igualmente alude a unas formas de pensar, de sentir y de actuar que expresan lo que causaba rechazo social. Esta cuestión ya fue puesta de manifiesto a raíz de las investigaciones realizadas desde la perspectiva de la microhistoria por autores como Emanuelle Le Roy Ladurie ${ }^{30}$ o Carlo Ginzburg ${ }^{31}$. A través de ellas se evidenció que lo excepcional o anormal podía informar sobre la centralidad. Es lo que Edoardo Grendi expresó con el término «excepcional-normal»: la excepcionalidad, presente en las fuentes judiciales, permitiría acceder a la normalidad en negativo y repensar los casos globales ${ }^{32}$. Arlette Farge señalaría al respecto: «La anormalidad y marginación dicen mucho sobre la norma y el poder político, y cada tipo de delito refleja un aspecto de la sociedad $»^{33}$.

${ }_{28}$ Ricardo Córdoba de la Llave en su minucioso estudio sobre el homicidio en la Andalucía bajomedieval analiza tres categorías de agresiones físicas según su gravedad, entre ellas, las que no suponían ningún riesgo para la vida y que judicialmente fueron menos perseguidas, además de los factores eximentes y atenuantes, como la defensa propia, las muertes accidentales...; vid. «El homicidio en Andalucía a fines de la Edad Media. Primera parte. Estudio». Clio \& Crimen. Revista del Centro de Historia del Crimen de Durango, n. ${ }^{\circ} 2$ (2005), pp. 331 y 341-356. Posteriormente publicado como libro por la Universidad de Granada en 2007 con el mismo título: El homicidio en Andalucía a fines de la Edad Media. Las referencias a este estudio se realizarán a partir de la versión de la revista Clio \& Crimen. Se podría decir que la violencia supuso una característica estructural de la sociedad medieval.

${ }^{29}$ I. Ramos VÁzQuez, «La represión de los delitos atroces en el derecho castellano de la Edad Moderna». Revista de Estudios histórico-jurídicos, n. ${ }^{\circ} 26$ (2004), pp. 255-299.

${ }_{30}$ Montaillou, aldea occitana, de 1294 a 1324. Madrid, Taurus, 1988 (1975). 1999 (1976).

${ }^{31}$ El queso y los gusanos. El cosmos, según un molinero del siglo XVI. Barcelona, Muchnik,

32 «Microanalisi e storia sociale». Quaderni Storici, n. 35 (1977), pp. 506-520.

33 La atracción del archivo. Valencia, Edicions Alfons el Magnànim, 1991 (1989), p. 26. 


\section{LA MODERNIZACIÓN DE LA CRIMINALIDAD MEDIEVAL A PARTIR DE SU ANÁLISIS CUANTITATIVO}

Desde los años 60 del siglo xx el análisis cuantitativo lo impregnó todo ${ }^{34}$, desde las cuestiones económicas hasta las sociales, continuando por las mentales, a partir de estudios sobre la demografía, la familia, la sexualidad o la muerte. En efecto, la cuantificación, el número, demostró que gracias a ella se podía alcanzar el tercer nivel o de la civilización, es decir, la mentalidad ${ }^{35}$. Pioneros en la aplicación del método cuantitativo y la utilización de documentación serial para analizar las actitudes y los comportamientos ante la muerte fueron François Lebrun ${ }^{36}$ o Michel Vovelle ${ }^{37}$. Por tanto, las diversas temáticas de análisis histórico encontraron en la cuantificación un aliado para su desarrollo y la criminalidad no fue una excepción, gracias a la existencia de fuentes seriales, como los procesos criminales. Así, antes de que François Billacois propusiera investigar la historia de la criminalidad en $1967^{38}$, los discípulos de Pierre Chaunu comenzaron a estudiarla desde esa perspectiva en el Centro de Investigación de Historia Cuantitativa de la Universidad de Caen (Normandía), fundado en 1966.

En 1962 Bernadette Boutelet realizó una memoria de diplomatura dirigida por Pierre Chaunu y centrada en la documentación judicial de una pequeńa localidad normanda llamada Pont-de-l'Arche. Aunque sólo pudo analizar 88 procesos criminales, la mitad de ellos correspondientes al período 1587-1646 y la otra mitad al de 1769-1789, alcanzó las siguientes conclusiones: que la criminalidad entre 1587 y 1646 se caracterizaba por la preponderancia de los delitos violentos (aproximadamente $2 / 3$ de los procesos) y perpetrados mayoritariamente por varones; y que, por el contrario, la criminalidad entre 1769 y 1789 era mucho más compleja y, aunque todavía persistía la violencia, ésta se había visto atenuada y había cedido su protagonismo a una criminalidad caracterizada por el fraude y la estafa, es decir, por los delitos contra la propiedad.

En otras palabras, Boutelet intuía un cambio de modelo criminal a partir de finales del Antiguo Régimen y suponía el paso desde la violencia «vers une cri-

${ }^{34}$ P. Chaunu, «Histoire quantitative ou histoire sérielle». Cahiers Vilfredo Pareto, t. III (1964), pp. 165-176; P. VILAR, «Pour une meilleure compréhension entre économistes et historiens. Histoire quantitative ou économique rétrospective?». Revue Historique, t. CCXXIII (1965), pp. 293 312; P. Chaunu, «Les dépassements de l'histoire quantitative: retrospective et perspective». Mélanges de la Casa de Velázques, t. 8 (1972), pp. 647-685.

$35 \mathrm{P}$. Chaunu, "Un nouveau champ pour l'histoire sérielle, le quantitatif au troisième niveau", en Mélanges en l'honneur de Fernand Braudel. T. I. Histoire économique du monde méditerranéen 1450-1650. Toulouse, Privat, 1972, pp. 105-127.

${ }^{36}$ Les hommes et la mort en Anjou au 17 e et 18 e siècles. Essai de démographie et de psychologie historiques. Paris-La Haye, 1971.

37 Piété baroque et déchristianisation en Provence au XVIII siècle. Les attitudes devant la mort d'après les clause des testaments. Paris, Plon, 1973.

38 «Pour une enquête sur la criminalité dans la France d'Ancien Régime». Annales ESC (mars-avril 1967), pp. 340-349. 
minalité d'escroquerie»; pero también señalaba que esa hipótesis normanda debía verse confirmada por otros estudios que pudieran acceder a un volumen mayor de documentación procesal que la analizada por ella ${ }^{39}$. A partir de estas conclusiones el propio Pierre Chaunu propuso a Bernadette Boutelet subtitular su investigación con el siguiente axioma: «De la violence au vol; en marche vers l'escroquerie $»^{40}$. Con él pretendía formular la teoría de que hasta el siglo XviıI persistió un modelo de criminalidad surgido en la Edad Media y basado en la violencia, y que con posterioridad cambió de signo pasando a otro modelo basado en el fraude: de la violencia al robo. Había nacido el paradigma cuantitativo de modernización de la criminalidad.

Dentro del propio marco geográfico francés distintos historiadores trataron de comprobar la validez de esta proposición ${ }^{41}$. Jacques Chiffoleau, por ejemplo, analizó el registro criminal de la corte temporal de Avignon durante el siglo xIV y verificó una preponderancia de los delitos violentos (agresiones, peleas, homicidios, asesinatos e incluso también injurias, entendidas como violencia verbal), frente a una menor presencia de atentados contra la propiedad, lo que achacó a la ausencia de una mentalidad economicista que no valoraba la propiedad en igual medida que lo haría la sociedad burguesa. Planteó que esa "criminalité d'Ancien Régime» habría surgido a raíz de la crisis bajomedieval y que se modificaría a partir del XVIII ${ }^{42}$.

A otro lado del canal de la Mancha, y a comienzos de los años 80, también vieron la luz diversos estudios que, a partir de esa metodología cuantitativa, buscaban analizar la evolución de la criminalidad en la Inglaterra de los siglos XIII al XIX. Dos serían los autores que incidirían sobre el proceso de disminución de la violencia de sangre y no tanto en la segunda derivada de la hipótesis normanda de Boutelet-

39 «Etude par sondage de la criminalité dans le bailliage du Pont-de-l'Arche (XvII ${ }^{\mathrm{e}}-\mathrm{XVIII}^{\mathrm{e}}$ siècles)». Annales de Normandie, n. 4 (1962) pp. 235-262.

40 «Etude par sondage de la criminalité dans le bailliage du Pont-de-l'Arche», p. 235.

${ }^{41}$ En la revista Annales de Normandie en los ańos siguientes a la publicación del estudio de Boutelet vieron la luz otros como el de J.C. Gégot en 1966 o el de P. Crepillon en 1967. Otras investigaciones basadas en series estadísticas que mostrarían una evolución similar del delito fueron las de Y.-M. Bercé en 1968 ("Aspects de la criminalité au Xvire siècle». Revue Historique, pp. 33-42), P. Deyon en 1972 («Délinquance et repression dans le Nord de la France au Xvirie siècle». Bulletin de la Société d'Histoire Moderne, n. ${ }^{\circ}$ 20, pp. 10-15), E. Le Roy Ladurie, en 1973 ("La décroissance du crime au XviII siècle, bilan d'historiens». Contrepoint, 9, pp. 227-233) o B. Garnot en 1981 ("Délits et châtiments en Anjou au Xviıre siècle». Annales de Bretagne et des pays de l'Ouest, n. ${ }^{\circ} 88-3$, pp. 283-304). Precisamente este último autor ha expresado esa transición de un modelo criminal a otro en los siguientes términos: «Les violents font place aux voleurs», vid. «L'Historiographie de la criminalité pour la periode moderne», en B. Garnot (dir.), Histoire et criminalité de l'Antiquite au XXe siècle. Nouvelles aproches, Dijon-Quetigny, Université de Bourgogne, 1992, p. 26.

42 «[...] où les courps, les rixes, les injures et les homicides l'emportent toujours nettement sur les vols et les atteintes à la propieté. Et ce véritable système de transgression, que l'ont voit apparaître dans les sources pendant la crise du XIV et du XV'e siècle (mais n'est-il pas né avant, au XIII ${ }^{e}$, ou même XII ${ }^{\mathrm{e}}$ siècle, quand l'essor urbain modifie certains équilibres traditionels?) ne se défait lentement qu'à la fin du XVIII ${ }^{\mathrm{e}}$ siècle et au XIX ${ }^{\mathrm{e}}$ siècle, au moment où les condition économiques et sociales subissent de nouveau une mutation décisive»; vid. Les justices du pape. Délinquance et criminalité dans la région d'Avignon au XIVè siècle. Paris, Publications de la Sorbonne, 1984, p. 111. 
Chaunu, esto es, el paso a una criminalidad patrimonial: el sociólogo Ted R. Gurr ${ }^{43}$ y el historiador Lawrence Stone ${ }^{44}$. Los resultados que obtuvieron pueden sintetizarse en dos grandes aspectos. 1) Los índices de violencia homicida en la Inglaterra del siglo XIII fueron dos veces más elevados que los correspondientes a los siglos XVI y XVII; y éstos a su vez lo fueron hasta cinco veces más que los de la sociedad contemporánea inglesa de comienzos de la década de los años 60 y 70 del siglo xx. Por tanto, ambos argumentaron que acontecía un descenso de la violencia interpersonal desde la Edad Media al tiempo actual y situaron el punto de inflexión entre los siglos XVII y XVIII, cuando se agudizó la caída. 2) También comprobaron otro cambio de tendencia: en la Edad Media la violencia tenía por protagonista a vecinos, amigos o forasteros implicados en peleas de taberna ocasionadas por la bebida y el juego o involucrados en conflictos internos de la sociedad local, y en menor medida se debía a la existencia de conflictos familiares. Sin embargo, con posterioridad la violencia intrafamiliar adquiriría un mayor protagonismo en la estadística criminal, pasando de representar el $8 \%$ en el siglo XIV al $50 \%$ en la actualidad.

No obstante, otras investigaciones sobre el mismo marco geográfico británico ponían en solfa estos resultados y evidenciaban que se habían sobrevalorado los índices de violencia y que, por el contrario, se había infravalorado la presencia de los delitos contra el patrimonio. Así, Alan Macfarlane, en su estudio sobre Westmorland en el siglo XVII, mostraba una sociedad excepcionalmente pacífica y libre de violencia, con un mayor predominio de los delitos contra el patrimonio ${ }^{45}$. Estos resultados de McFarlane fueron criticados por Lawrence Stone, señalando que una única localidad no ofrecía un marco poblacional suficientemente grande como para obtener conclusiones estadísticas significativas ${ }^{46}$. Barbara A. Hanawalt, por su parte, para el período bajomedieval, demostraba unos índices de delitos contra la propiedad similares a los que se podían cuantificar para los siglos XVI y XVII ${ }^{47}$. En consecuencia, James A. Sharpe concluyó que los resultados obtenidos en los archivos ingleses demostraban que la interpretación «de la violence au vol» $\mathrm{o}$ «from violence to theft» era un lamentable error ${ }^{48}$.

También en la década de los años 80 se publicaron nuevas investigaciones basadas en métodos cuantitativos o de historia serial, pero centradas en el marco

43 «Historical trends in violent crime: a critical review of the evidence». Crime and Justice: An Annual Review of Research, III (1981), pp. 295-353. El indicador que utilizó fue el homicidio por cada 100000 habitantes, que ya había sido adoptado previamente por James B. Given, Society and homicide in 13th century England, pp. 35-40.

${ }^{44}$ "Interpersonal violence in English society 1300-1980». Past \& Present, n. ${ }^{\circ} 101$ (1983), pp. 22-33.

${ }^{45}$ The justice and the Mare's Ale: Law and disorder in Seventeenth-Century England. New York, 1981.

46 «Interpersonal violence», p. 22.

47 «Economic influences on the pattern of crime in England, 1300-1348». American Journal of Legal History, 18 (1974), pp. 281-297; «Violent death in Fourteenth and Early Fifteenth century England». Comparative Studies in Society and History, n. 18 (1976), pp. 297-320.

48 Crime in Early Modern England 1550-1750. London, 1984, p. 59. 
geográfico de Escandinavia. Eva Österberg, por ejemplo, analizó los registros procesales de la Suecia de los siglos XIv/Xv a XVIII/XIX y llegó a la conclusión de que se invertían los términos del paradigma cuantitativo de modernización de la criminalidad. Así, en lugar «de la violence au vol» sería "du vol à la violence», ya que los casos de robo fueron superiores en el período 1545-1560 que en el de 1615-1645. Además, las tasas per cápita de violencia letal disminuyeron entre los siglos XV y XVIII, para volver a aumentar, aunque ligeramente, a principios del XIX, y disminuir ya a niveles más bajos entre finales del xIx y principios del xx. Sin embargo, esa disminución de la violencia homicida no fue acompańada de un incremento de los delitos de robo ${ }^{49}$.

Los estudios de Sharpe o Österberg, entre otros, ponían en cuestión la hipótesis «de la violence au vol», pero sí observaban el descenso multisecular de la violencia homicida desde las altas tasas de la Edad Media hasta las marginales del siglo XIX. En consecuencia, ¿realmente se producía el cambio de tendencia o de modernización de la criminalidad medieval?; ‘ُue un proceso universal?; ¡¿cuándo se supone que tuvo lugar?; ¡ ¿el proceso de declive de las tasas de violencia homicida fue lineal o tuvo altibajos?; ¿qué lo provocó, un proceso de civilización de los comportamientos o un proceso de disciplinamiento?

\section{LÍMITES INTERPRETATIVOS Y METODOLÓGICOS DEL PARADIGMA CUANTITATIVO DE MODERNIZACIÓN DE LA CRIMINALIDAD MEDIEVAL ${ }^{50}$}

\subsection{Problemas ligados a la estadística Criminal o a la Representatividad DE LAS FUENTES JUDICIALES}

No siempre se ha sabido soslayar adecuadamente la diferencia existente entre la criminalidad registrada y la real ${ }^{51}$. En efecto, los registros conservados sobre la actuación de la justicia pública, especialmente de la Edad Media y Moderna, no

49 «Violence Among Peasants Comparative on the 16th and 17th Century Sweden», en G. Rystad (ed.), Europe and Scandinavia. Aspects of the process of integration in the 17th century, Lund, Scandinavian University Books, 1983, pp. 257-275; "Gender, class, and the courts: Scandinavia», en C. Emsley \& L.A. Knafla (eds.), Crime history and histories of crime. Studies in the historiography of crime and criminal justice in Modern History, Wetport-London, Greenwood Press, 1996, pp. 47-65.

${ }^{50}$ Desde el medievalismo hispano una de las primeras voces críticas con este modelo fue José Miguel Mendoza Garrido en su tesis doctoral publicada con el título de Delincuencia y represión en la Castilla bajomedieval: los territorios castellano-manchegos, Granada, Grupo Editorial Universitario, 1999, concretamente en las pp. 59-67.

${ }^{51}$ C. Gauvard, «Les sources de la fin du Moyen Âge peuvent-elles permettre une aproche statisque du crime?», en P. Contamine \& T. Dufour \& B. Schener B (eds.), Commerce, finances et société (XI-XVI). Menlanges Henri Dubois, 1993, pp. 469-488. La criminología define la "criminalidad real» en los siguientes términos: «La totalidad de los delitos que efectivamente se realizan [...] independientemente de que hayan sido o no investigados o siquiera conocidos por las autoridades o los particulares», A. Reyes Echeandía, Criminología. Colombia, Temis, 1987 (8. ${ }^{a}$ ed.), p. 21. 
muestran más que una parte de la criminalidad real, ya que hubo delitos que no fueron denunciados, o que no pudieron ser juzgados porque sus autores no se capturaron, o que se resolvieron extrajudicialmente por cauces privados, o que no fueron registrados porque dado su carácter menor (hurto, vagabundeo, prostitución...) las autoridades se limitaron a expulsar de su jurisdicción a los culpables sin entablar juicio alguno. Por tanto, existe un grave problema de cifras negras del delito o de índices de ocultación («dark figure» $\mathrm{o}$ «black date») que hay que tener presente y que resulta muy difícil cuantificar. En definitiva, los tribunales de justicia no reflejan la evolución de la criminalidad real, sino la actividad y el funcionamiento de la justicia. No se pueden cuantificar los delitos perpetrados, tan sólo su persecución ${ }^{52}$. Benoît Garnot cifra los índices de criminalidad perseguida en menos de 10 habitantes por 100000 , lo que resulta «très insuffisant pour tirer des conclusions valables pour la société dans son ensemble» ${ }^{53}$.

Por si fuera poco este problema, también hay que tener presente que en la Edad Media y Moderna coexistieron múltiples jurisdicciones, cada una de ellas especializada en la persecución de determinados delitos o delincuentes, además de varias instancias procesales: tribunales de la justicia real (primera instancia y apelación), seńoriales, eclesiásticos (arcediano, obispo), consulados (delitos cometidos por mercaderes), hermandades (delitos perpetrados en despoblado), inquisitoriales, etc. ${ }^{54}$. Por tanto, esa pluralidad de jurisdicciones e instancias procesales hace que la aproximación a la totalidad del delito sea sumamente difícil, por no decir imposible, si no se cruzan los datos, cuando existen. Sí es factible estudiar la actuación de esos tribunales frente al delito, pero no extrapolar sus resultados al resto de la sociedad. Eso se comprueba con el tribunal de los alcaldes de Hermandad de la Corona de Castilla de finales de la Edad Media, jurisdicción muy estudiada desde el punto de vista del derecho y de las instituciones, pero en menor medida desde el análisis de su actuación judicial de persecución del delito, preferentemente del cometido en despoblado y en caminos ${ }^{55}$. Los estudios realizados por José María Sánchez Benito sobre las Hermandades viejas de Toledo, Talavera y Ciudad Real durante el período 1424-1506 proyectan los siguientes resultados: $64,5 \%$ de robos y $14 \%$ de actos de

52 V. BAILEY, "Reato, giustizia penale e autoritè in Inghileterra». Quaderni Storici, n. ${ }^{\circ} 44$ (1980), p. 591; R. Narbona VizCaíno, Malhechores, violencia y justicia ciudadana en Valencia bajomedieval (1369-1399). Valencia, Ayuntamiento de Valencia, 1990, p. 62; F. SEgurA, «Raíces historiográficas», pp. 608-610.

53 «L'Historiographie de la criminalité pour la periode moderne», p. 29.

${ }^{54}$ A modo de ejemplo puede citarse el trabajo de José Luis de las Heras, donde estudia la administración de justicia durante la monarquía de los Austrias, incidiendo en los tribunales ordinarios, privilegiados (Hermandad, Mesta, Universidad...) y delegados para ciertas materias (consulados, reales sitios...), vid. La justicia penal de los Austrias en la Corona de Castilla. Salamanca, Universidad de Salamanca, 1994, pp. 55-147.

55 I. BAZÁn (ed.), La persecución de la delincuencia en despoblado en la Edad Media: las Hermandades concejiles y otras instituciones afines, núm. monográfico de Clio \& Crimen. Revista del Centro de Historia del Crimen de Durango, n. ${ }^{\circ} 3$ (2006), pp. 6-529. 
violencia $^{56}$. Igualmente, el propio Sánchez Benito también analizó los delitos perseguidos por la Santa Hermandad, instituida por los Reyes Católicos para la geografía de toda la Corona de Castilla, y comprobó que entre los años 1490-1493 se habían perpetrado 22 muertes frente a 108 robos $^{57}$. Siguiendo la estela de Sánchez Benito, Juan Miguel Mendoza estudió en detalle la criminalidad perseguida por la Hermandad de Ciudad Real a través de los libros de cuentas correspondientes a los años 1491-1525 y documentó la existencia de 75 casos de violencia frente a 309 contra la propiedad, lo que suponía respectivamente el $15,75 \%$ y $64,91 \%$ de total de los delitos ${ }^{58}$. Estos resultados evidencian que en caminos y despoblados quienes sufrían el delito eran viajeros, transportistas y comerciantes, y que lo que buscaban sus asaltantes eran bienes, lo cual no quiere decir que para conseguirlos no se procediera con violencia. Cuando se observa de cerca la actuación delictiva de uno de esos «malhechores feudales», como los denominara Salustiano Moreta ${ }^{59}$, caso del señor de la torre de Berna en la merindad de Durango (Vizcaya), se comprueba que sus acciones depredadoras en caminos y caseríos circundantes tenían como objetivo principal la apropiación de ganado, dineros y demás bienes. Contra este señor se levantó la villa de Durango en unión de la Hermandad de Vizcaya y derrocaron su casa torre ${ }^{60}$.

En definitiva, dependiendo del tribunal elegido para el estudio los resultados diferirán, como ya apuntó Bronislaw Geremek. Este historiador polaco analizó la criminalidad a través de los archivos judiciales del Châtelet parisino, donde se recogía la acción del preboste que actuaba en nombre del rey, y de las cortes señoriales de Saint-Germain-des-Prés, Sainte-Geneviève, Saint-Martin-des-Champs y del capítulo de Nôtre-Dame. Pues bien, según los datos del Châtelet, el 66,1\% del delito registrado era de robo y el $4,7 \%$ de homicidio; por el contrario, según los archivos de las cortes señoriales, el $76,6 \%$ eran delitos contra las personas y el $7 \%$ robos $^{61}$.

Otro problema que hay que resolver es cómo incluir o contabilizar dentro de la estadística criminal las muertes acaecidas en los enfrentamientos entre linajes o guerras privadas. En el caso del País Vasco, por ejemplo, la crónica Bienandanzas e fortunas, escrita en el último cuarto del siglo Xv por el pariente mayor Lope García

\footnotetext{
56 Santa Hermandad Vieja de Toledo, Talavera y Ciudad Real (siglos XIII-XV). Toledo, 1987, p. 276.

57 «Criminalidad en época de los Reyes Católicos. Delincuentes perseguidos por la Hermandad", en Estudios de Historia Medieval en homenaje a Luis Suárez Fernández, Valladolid, Universidad de Valladolid, 1991, p. 418.

58 Violencia y delincuencia en el Campo de Calatrava a fines de la Edad Media. Ciudad Real, Instituto de Estudios Manchegos, 1992, pp. 40-44. Sobre estas cuestiones abunda en su tesis doctoral Delincuencia y represión en la Castilla bajomedieval...

${ }_{59}$ Malhechores-feudales: violencia, antagonismo y alianzas de clases en Castilla, siglos XIII-XIV. Madrid, Cátedra, 1978.

${ }^{60}$ I. BAZÁN, «El refugio de la delincuencia señorial. Torres y casas fuertes en el País Vasco: el ejemplo de la Torre de Berna». Sancho el Sabio. Revista de Cultura e Investigación Vasca, n. ${ }^{\circ} 8$ (1998), pp. 23-50.

${ }^{61}$ Les marginaux parisiens aux XIVe et XVe siècles. Paris, Flammarion, 1976, pp. 62-74.
} 
de Salazar ${ }^{62}$, se hace eco de las luchas sangrientas entre los diferentes bandos y cabezas de linajes, y sus páginas están salpicadas de muertes al margen de una contienda abierta, pero dentro de ese contexto ${ }^{63}$. Estas guerras privadas eran, como argumenta Pieter Spirenburg, un síntoma del bajo nivel de formación del Estado y de pacificación del territorio, por lo que esas muertes deberían ser dejadas de lado y reparar en aquellas otras que la débil administración de justicia consideraba totalmente ilegales y las perseguían penalmente como un delito de homicidio ${ }^{64}$. Un ejemplo de esa administración débil frente a la violencia de las guerras privadas de los linajes para el mismo caso del País Vasco sería el de las Hermandades, que desde su creación por las ciudades y provincias a finales del siglo XIV no consiguieron imponerse hasta la segunda mitad del siglo xv, gracias al apoyo de la Corona y al mismo tiempo que iban creando, especialmente en las provincias de Álava y Guipúzcoa, un fuerte poder centralizado $^{65}$. Por tanto, este tema de las guerras privadas introduce una cuestión sumamente interesante, cual es la necesidad de diferenciar entre criminalidad y violencia, como la ligada a circunstancias de inestabilidad política y socioeconómica.

Hay que tener también presente el hándicap que supone el deficiente estado de conservación de las series documentales en los archivos ${ }^{66}$, cuando no su desaparición por siniestros, infortunios o simplemente por negligencia consciente, como en el caso del proceso seguido contra los herejes de Durango a mediados del siglo $\mathrm{XV}$ y que se conservaba en la iglesia parroquial de la villa, pero que a principios del siglo XIX fue destruido para evitar el oprobio que ocasionaba a los vecinos ${ }^{67}$. Ricardo Córdoba de la Llave ha puesto el acento sobre esta cuestión en un sugerente estudio para el caso de la Corona de Castilla: la «carencia de una documentación auténti-

${ }^{62}$ M. ${ }^{a}$ C. Villacorta, Edición critica del Libro de las buenas andanças e fortunas que fizo Lope Garçía de Salazar. Bilbao, Universidad del País Vasco, 2005.

${ }_{63}$ Una síntesis sobre el particular J.R. Díaz de Durana, «Violencia, disentimiento y conflicto en la sociedad vasca durante la Baja Edad Media: la lucha de bandos, estado de la cuestión de un problema historiográfico", en Violencia y conflictividad en la sociedad de la España bajomedieval, Zaragoza, 1994, pp. 27-58; J.R. Díaz De Durana (coord.), La lucha de bandos en el País Vasco: de los Parientes Mayores a la hidalguía universal. Guipúzcoa, de los bandos a la provincia (siglos XIV a XVI). Bilbao, Universidad del País Vasco, 1998.

${ }^{64}$ "Long-tern trends in homicide: theretical reflections and Dutch evidence, fifteenth to twentieth centuries», en E.A. Johnson \& E.H. Monk Konen (dirs.), The Civilization of crime. Violence in town and country since Middle Ages, Urbana-Chicago, University of Illinois Press, 1996, pp. 73-74.

65 J.L. Orella Unzúe, "Las hermandades vascas en el marco de la Santa Hermandad como instrumento de control de delitos e impartición de penas», en I. BAZÁN (ed.), La persecución de la delincuencia en despoblado en la Edad Media, pp. 68-133; I. BAZÁn, «The formation of the basque institutional framework at the end of the Middle Ages and its historical legacy", en Peoples, identities and regions. Spain, Russia and the challenges of the multi-ethnic state, Moscow, Russian Academy of Sciences, 2015, pp. 79-92.

${ }^{66}$ Como señalaba Jacques Chiffoleau en relación con los archivos de la Corte Temporal de Avignon conservados en el Vaticano: «Sont très lacunaires» $\mathrm{y}$ «ne nous permettront jamais d'établir des statistiques criminelles précises»; «La violence au quotidien», pp. 332 y 341.

${ }^{67}$ I. BAZÁn, Los herejes de Durango y la búsqueda de la Edad del Espiritu Santo en el siglo XV. Durango, Museo de Arte e Historia de Durango, 2007, pp. 151-162. 
camente judicial». Es decir, los investigadores se enfrentan al problema de la escasez de procesos o pleitos completos conservados y, en consecuencia, se ven obligados a recurrir y conformarse con fragmentos de la actuación procesal como son, por ejemplo, las sentencias, las declaraciones de testigos, los autos judiciales, etc. Además, a esa escasez de procesos hay que añadir dos problemas más: por un lado, la documentación judicial conservada muestra un laconismo de detalles relacionados con las circunstancias del delito; y, por otro lado, la escasa fiabilidad de los hechos referidos, ya que las declaraciones de las partes, con el fin de alcanzar sus objetivos, ya sea demostrar la culpabilidad o la inconciencia, argumentaban y construían un discurso ad hoc ante los tribunales ${ }^{68}$.

En relación con el problema de los índices de ocultación de la criminalidad real («dark figure» $\mathrm{o}$ «cifras negras») se encuentra el fenómeno de la resolución de los conflictos entre las partes enfrentadas al margen de los tribunales de justicia, recurriendo a mecanismos de acuerdo como la composición privada y al arbitraje. Esta forma de resolución de conflictos y de restauración del orden sin recurrir a los tribunales ha dado mucho que hablar e incluso ha propiciado el establecimiento de nuevos paradigmas en la historiografía de la criminalidad, concretamente el conocido con el nombre en inglés de "reluctant litigators» («plaideurs réticents» en francés o litigantes/pleiteantes reticentes en español). Los autores de este paradigma, Bruce Lenman y Geoffrey Parker ${ }^{69}$, consideraron que no recurrir a los tribunales de justicia para la resolución de conflictos era un fenómeno especialmente destacable en el caso inglés debido a las peculiaridades de su sistema procesal, con un fuerte peso de las prácticas consuetudinarias de control social. Lógicamente, este proceder repercutía en la estadística criminal registrada. Sin embargo, la realidad histórica de recurrir a la «justicia no oficial» para alcanzar un acuerdo entre partes enfrentadas fue un expediente muy extendido por toda la geografía europea, como ya evidenciaron primero Yves Castan ${ }^{70}$ y Alfred Soman ${ }^{71}$, y más tarde los autores de la obra colectiva dirigida por Benoît Garnot ${ }^{72}$.

68 R. Córdoba de la Llave, "Violencia, delincuencia e inestabilidad social en la Castilla bajomedieval: los límites de la documentación», en L'Espai del mal, Lleida, Pagès Editors, 2005, pp. 319-338.

69 "The State, the Community and the modern law in Early Modern Europe», en V.A.C. Gattrel, B. Lenman \& G. Parker (eds.), Crime and the law. The social history of crime in Wester Europe since 1500, London, 1980, pp. 11-48.

70 Honnêteté et relations sociales en Languedoc 1715-1780. Paris, Plon, 1974.

71 "L'infrajustice à Paris après les archives notariales». Histoire, Économie et Société, n. 3 (1982), pp. 369-376.

72 L'Infrajudiciaire du Moyen Âge à l'Époque Contemporaine. Dijon, 1996. Sobre esta cuestión el propio Garnot tiene un trabajo ya clásico: "Justice, infrajustice, parajustice et extra justice dans la France d'Ancien Régimen». Crime, Histoire \& Sociétés / Crime, History \& Societies, vol. 4, n. ${ }^{\circ} 1$ (2000), pp. 103-120. En él define el concepto de «infrajusticia» en los siguientes términos: «On peut considérer en premier lieu qu'elle peut concerner tous les types de conflits que la justice est susceptible de traiter, au pénal bien sûr, mais aussi au civil, bref tout les conflits qui peuvent opposer entre eux les individus. En second lieu, l'infrajustice suppose une certaine organisation qui repose sur un consensus social, au moins au niveau local: en particulier l'intervention de tiers, individuels 
¿Qué argumentos justificaban esta práctica de recurrir a la composición o al arbitraje solicitando la intervención de mediadores, con ascendente moral en la comunidad, para resolver un conflicto y restaurar la paz al margen de los tribunales de justicia? Fundamentalmente tres: el argumento económico, el de la paz social y el de evitar la infamia. El primero alude al elevado coste económico que para una familia suponía optar por la vía judicial para alcanzar la satisfacción o vindicta por el daño sufrido. Estaban los honorarios de los abogados y de los procuradores, las costas judiciales, etc. Todos esos gastos se incrementaban si el proceso era especialmente largo o había que continuarlo en las diferentes instancias de apelación. Por el contrario, el arbitraje y la mediación facilitaban una solución menos costosa y más rápida. El argumento de la paz social se refiere a que no era raro que los familiares y vecinos estuvieran especialmente interesados en que la disputa se zanjara amistosamente y con la conformidad de las partes, evitándose de este modo que fuera el germen de ulteriores conflictos que envenenaran la convivencia en la comunidad, afectando a terceras partes. Y el argumento de la infamia expresa que gracias a la conciliación privada se solucionaban conflictos ligados al honor (violación, adulterio...) sin que fueran aireados por toda la comunidad y sin que los protagonistas estuvieran en boca de todos. Junto con estos argumentos también debe traerse a colación otro más para justificar ese acogerse a la justicia no oficial: que las partes enfrentadas pertenecieran a una cofradía, vecindad, calle... en cuyos estatutos u ordenanzas se estableciera que antes de acudir al juez dirimieran sus diferencias de esa forma

ou collectifs, pour parvenir à un règlement entre les parties ou pour l'entériner, règlement qui a concrètement force d'obligation morale et sociale aux yeux non seulement des parties, mais de tous les membres de la communauté concernée; l'infrajustice a donc un caractère public ou semi-public, parfois même officiel (lorsqu'elle implique un notaire, par exemple, ou une institution). C'est dire, en troisième lieu, que les affaires qui bénéficient de règlements privés n’appartiennent pas au domaine de l'infrajustice» (p. 109). Sobre la "parajusticia» señala: «La justice et l'infrajustice supposent la publicité, tandis que la parajustice se caractérise par des procédures privées, sans intervention active d'un tiers, qui se concrétisent soit par des arrangements soit par des vengeances, lesquels ont finalement les uns et les autres le même but, qui est de rétablir un équilibre social préalablement brisé par une transgression (comme l'infrajustice, par conséquent, mais par des moyens différents)» (p. 113). Y, por último, la «extrajusticia» sería: «L'extrajustice est le seul mode d’appréhension de la criminalité qui ne débouche sur aucun règlement de celle-ci; à la différence de la justice, de l'infrajustice et de la parajustice, elle ne cherche pas à résoudre des conflits. Cette situation d'extrajustice se décline sur deux modes: celui de la criminalité subie contre leur gré par les habitants, et celui de la criminalité qu'ils tolèrent volontairement» (p. 115). Una cuestión sobre la que reflexionar es la de si el término «infrajusticia» es apropiado del todo cuando remite a un mecanismo de resolución de conflictos legalmente admitido y reglamentado en la sociedad medieval y moderna, y cuando recurrían a este sistema de arbitraje incluso las monarquías y los linajes enfrentados. Tomás A. Mantecón admite el término «infrajusticia» y lo define como «la justicia lograda con intervención no oficial». Igualmente considera que la «infrajusticia» puede ser una «justicia alternativa a la oficial» o "complementaria a la oficial». En el primer caso el tribunal ignoraba el conflicto y su resolución; y, en el segundo caso, el conflicto llegaba el juzgado, pero al mismo tiempo las partes negociaban para lograr un acuerdo fuera del tribunal. En este sentido señala que en Cantabria más de las tres cuartas partes de las causas sin sentencia se resolvieron a través de la vía «infrajudicial». Vid. «El peso de la infrajudicialidad en el control del crimen durante la Edad Moderna». Estudis, n. 28 (2002), pp. 48, 59 y 68. 
y si así no lo hicieran serían multados e incluso expulsados. Ejemplos en este sentido son los estatutos de las cofradías de la Vera Cruz y de las Terceras Órdenes de Cantabria $^{73}$; las ordenanzas de las vecindades de Vitoria, Laguardia y Pamplona ${ }^{74}$, al igual que los barrios de Leiden ${ }^{75}$; o en el «modelo pólder» holandés del que habla Pieter Spierenburg como mecanismo de resolución de conflictos relacionados con el aumento del agua del mar en los territorios desecados ${ }^{76}$. En resumen, la mediación y la conciliación tuvieron un peso importante para resolver disputas, lo que demuestra, por un lado, que la justicia oficial en la Edad Media y Moderna no dispuso del monopolio a la hora de imponer la paz entre partes enfrentadas, sino que convivieron y cooperaron ambos sistemas; y, por otro, como advirtió Claude Gauvard, que «brutalité de l'homme médiéval», vulgarizada por una lectura rápida de las tesis de Norbert Elias, no se ajustaba del todo a la realidad ${ }^{77}$. Por último, también podrían argüirse razones prosaicas para recurrir al arbitraje y a la mediación, como en el caso de la Galicia del Antiguo Régimen, donde se ha constatado una renuencia a interponer pleitos como consecuencia de la lejanía física de los aldeanos respecto de los tribunales de justicia, además del elevado coste de los mismos ${ }^{78}$. La importancia de la perspectiva «infrajudicial» ha llevado a Xavier Rousseaux a preguntarse si no será el leitmotiv de la renovación de la historia de la criminalidad ${ }^{79}$.

Pero ¿̇hasta qué punto los datos de la composición privada recogidos en el intrumentum pacis notarial, cuando se hace ${ }^{80}$, pueden ayudar a completar las cifras

73 T.A. Mantecón, «El peso de la infrajudicialidad», p. 72.

${ }^{74}$ I. BAZÁN, «Control social y control penal: la formación de una política de criminalización y de moralización de los comportamientos en las ciudades de la España medieval», en S. CASTillo y P. Oliver (coords.), Las figuras del desorden. Heterodoxos, proscritos y marginados, Madrid, siglo XXI, 2006, pp. 255-283. Por ejemplo, en el caso de Vitoria, los vecinos enfrentados daban cuenta del conflicto a la asamblea vecinal y ésta designaba a dos personas, entre las que tuvieran una menor afinidad con ellos, para que junto con los rectores de la vecindad (elegidos anualmente) dilucidaran sobre el articular.

${ }^{75}$ Los vecinos nombraban dos hombres buenos para resolver las tensiones entre los residentes del barrio; Herman Roodenburg, "The "hand of friendship" ", en J. Bremmer \& H. Roodenburg (eds.), Cultural history of gesture: from antiquity to the present day, Cambridge, 1991, pp. 152-189.

76 "L'Homicide et la loi en la République des Pays-Bas du Nord: un pays pacifique?», en L. Mucchielli \& P. Spierenburg (dirs.), Histoire de l'homicide en Europe. De la fin du Moyen Âge à nos jours, Paris, La Découvert, 2009, pp. 53-83.

77 "Conclusion", en Le règlement des conflits au Moyen-Âge, Paris, Publications de la Sorbonne, 2001, pp. 373-374.

${ }^{78}$ I. Dubert Historia de la familia en Galicia durante la Edad Moderna, 1550-1830. A Coruña, Ediciós do Castro, 1992, pp. 330-331 y 354-355.

79 «Historiographie du crime et de la justice criminelle dans l'espace français (1990-2005). Partie I», párrafo 50, consultado el 30 de septiembre de 2016, http://chs.revues.org/203.

${ }_{80}$ No era infrecuente que el resultado de estos acuerdos privados se plasmara por escrito ante notario, quedando registrados en sus protocolos. Por eso la documentación notarial es un buen semillero para el estudio la acción extrajudicial. A modo de ejemplo se puede traer a colación el estudio de M. ${ }^{a}$ Á. Martín Miguel, «Las relaciones extramaritales: documentos de estupro, desistimiento de esponsales y reconocimiento de hijos ilegítimos», en M. ${ }^{a}$ Rosario Porres (coord.), Apro- 
del delito? No es posible, como acertadamente ha señalado Pablo Pérez García ${ }^{81}$. Tan sólo ayudan a saber qué delitos se sometían con mayor frecuencia a este tipo de resoluciones, conocer alguno más no recogido en el registro judicial oficial y comprobar los argumentos que esgrimían las partes para recurrir a este tipo de expedientes. Si Lenman y Parker con su teoría querían señalar que no toda la delincuencia era registrada, tenían razón; pero no era cierto que las sociedades bajomedievales y modernas fueran litigantes reticentes, como demostraron diversas investigaciones. Por ejemplo, Jens C. Johansen y Henrik Stevnsborg analizaron la ciudad danesa de Elsneur durante la Edad Moderna y llegaron a contabilizar una media de 500 procesos anuales para una población de 5000 habitantes ${ }^{82}$. Igual ocurría en la Corona de Castilla durante la Edad Moderna, según demostró Richard L. Kagan, cuando el pleito se convirtió en un fenómeno sumamente popular al que recurrían todos los extractos sociales y cuya resolución registraba la administración de justicia a través de las cartas ejecutorias solicitadas por la parte que vencían en el juicio ${ }^{83}$.

Por tanto, la estadística criminal ${ }^{84}$ tan sólo permite acceder a una parte de la criminalidad registrada, alejada de la real, y a unos tipos de delitos más que a otros. Pero para conocer el impacto de los índices de criminalidad hay que ponerlos en relación con la demografía de cada momento histórico y aquí surge un nuevo problema derivado del hecho de que la Edad Media es una época preestadística que carece de censos de población y cuando existen son aislados y/o sin continuidad temporal. Aunque en el caso de la Edad Moderna las fuentes demográficas se incrementan, su calidad no mejora drásticamente. En consecuencia, la ausencia de un referente demográfico impide establecer una comparación con los índices de criminalidad, ya de por sí poco fiables, centrados en la tasa de homicidios ${ }^{85}$.

En relación con el empleo de las tasas de homicidio por cada 100000 habitantes como escala de medición y de cuantificación de la criminalidad para la Edad Medía, además del problema de las fuentes demográficas, Gerd Schwerhoff añade

ximación metodológica a los protocolos notariales de Álava (Edad Moderna), Bilbao, Universidad del País Vasco, 1996, pp. 213-220.

81 «Una reflexión en torno a la historia de la criminalidad». Revista d'Historia Medieval, n. ${ }^{\circ} 1$ (1990), p. 31.

82 «Hasard ou myopie. Réflexions autor de deux théories de l'histoire du droit». Annales ESC, 41-3 (1986), pp. 614-617.

${ }^{83}$ Pleitos y pleiteantes en Castilla, 1500-1700. Valladolid, Junta de Castilla y León, 1991. Kagan cita el testimonio del escribano Gabriel de Monterroso y Alvarado, en su obra Práctica criminal y civil: instrucción de scrivanos (Valladolid, 1566), cuando señalaba que "cada dia crezcan los pleitos y contiendas entre las gentes; está ya el mundo tan engolfado y metido en ellos que casi ninguna cosa se averigua si no por tela de juicio» (p. 31).

${ }^{84}$ Se puede decir que la estadística criminal nació en el siglo xix de la mano de Lambert A. Quetelet; vid. L. Rodríguez Manzanera, Criminología. México, Editorial Porrúa, 1981 (1979), pp. 315-323.

${ }^{85}$ Fórmula para el cálculo de la tasa de homicidios: $\mathrm{TH}=(\mathrm{NTH} / \mathrm{TP}) \times 100000$ habitantes. Donde TH es la tasa de homicidios; NTH el número total de homicidios; y TP la población total. Vid. Sistema Regional de Indicadores Estandarizados de Seguridad y Convivencia Ciudadana y Global Study on homicide 2013. Trends, contexts, data. Vienna, UNODC, 2014. 
dos problemas más. El primero tendría que ver con aquellas muertes que se contabilizan en una localidad, pero que realmente eran el resultado de unas heridas fatales causadas en otro lugar diferente. En este sentido refiere el caso de un oficial condenado a destierro por haber acuchillado a su mujer en Núremberg en 1392, pero que moría posteriormente en Bamberg a causa de las heridas. El segundo problema que aborda Schwerhoff es el de los homicidios sin premeditación sobrevenidos en el curso de las muchas reyertas de taberna o de calle acaecidas en las ciudades medievales de menos de 5000 o 10000 habitantes, aunque esta complicación también es extrapolable a períodos históricos posteriores. Así, tan sólo dos muertes no premeditadas registradas en una ciudad de 10000 habitantes arrojarían una desproporcionada tasa de homicidios de 20 por 100 000, con lo que este índice estaría deformando la realidad delictiva de esa localidad ${ }^{86}$. En este sentido, también habría que señalar que la tasa de homicidios se vería afectada al alza por el escaso desarrollo de la medicina medieval, ya que muchos de los implicados en simples reyertas acabarían falleciendo como consecuencia de las lesiones y heridas infectadas y mal curadas.

Este segundo problema planteado por Gerd Schwerhoff sobre el empleo de la tasa de homicidios por cada 100000 habitantes puede ser completado con el grave riesgo de ignorar la representación social del delito o del delincuente para una sociedad dada. Así, a fines de la Edad Media muchos de los implicados en actos de violencia, cuya consecuencia mortal podría engrosar los índices de la estadística criminal, al igual que los que proferían blasfemias, no casaban con el arquetipo de delincuente; es decir, un individuo marginado, amoral y socialmente peligroso. Antes al contrario, resultaban ser personas perfectamente integradas en la sociedad que por la defensa del honor se veían involucradas en acciones violentas con trágicas consecuencias, como ya puso de manifiesto Elisabeth Pavan en su estudio sobre la violencia en la Venecia bajomedieval ${ }^{87}$. Es más, tenían peor consideración social las personas que no desenvainaran la espada en defensa del honor familiar ${ }^{88}$. En definitiva, y como bien señala Juan Miguel Mendoza, a fines de la Edad Media la con-

${ }^{86}$ La Tasa de homicidios $=(2 / 10000) \times 100000=20$. $«$ Criminalized violence and the process of civilisation: a reappraisal». Crime, Histoire \& Sociétés / Crime, History \& Societies, vol. 6, n. ${ }^{\circ} 2$ (2002), p. 6. X. Rousseaux, B. Dauven y A. Musin señalan que «le taux pour 100000 habitants tend à surévaluer la présence de l'homicide dans les petites communautés démographiques», vid. "Civilisation des moeurs et/ou disciplinarisation sociale? Les sociétés urbaines face à la violence en Europe (1300-1800)», en L. Mucchielli \& P. Spierenburg (dirs.), Histoire de l'homicide en Europe de la fin du Moyen Âge à nos jours, Paris, La Découverte, 2009, p. 285. E. Monkkonen ha propuesto un mecanismo complejo de corrección para el cálculo de los homicidios por 100000 habitantes en poblaciones pequeñas y para sociedades preestadísticas; «New standards for historical homicide research». Crime, Histoire \& Sociétés / Crime, History \& Societies, vol. 5, n. ${ }^{\circ}$ (2001), pp. 5-26.

${ }^{87}$ «Violence, société et pouvoir à Venise (XIV-Xv siècles)». Melanges de l'École Française de Rome, 96 (1984), p. 914.

${ }^{88}$ Un ejemplo de un marido que se ve obligado a sacar su espada en defensa de su honor familiar como consecuencia del acoso sexual al que era sometida su mujer por un tercero es el analizado por I. BAZÁN en «María San Juan (Guernica, 1489-1490), una mujer acosada para forzar una relación sexual no consentida», en M.J. Fuente y R. Morán (eds.), Raíces profundas. La violencia contra las mujeres (Antigüedady Edad Media), Madrid, Polifemo, 2011, pp. 277-304. 
sideración de delincuente variaba «en función de su rango social, del tipo de infracción cometida y de contra quién la había cometido» ${ }^{89}$.

\subsection{Problemas ligados a la tipología del delito: ¿Es aCertado Centrar EL ANÁLISIS DE LA EVOLUCIÓN DE LA CRIMINALIDAD EXCLUSIVAMENTE EN EL INDICADOR DEL HOMICIDIO?}

El homicidio se convirtió prácticamente en el único referente para representar y medir la violencia y la evolución de la criminalidad. Dos razones pueden justificar esta elección. La primera porque, dada la enorme resonancia social del homicidio, sería un crimen de difícil ocultación y, por tanto, se encontraría registrado en la documentación judicial oficial ${ }^{90}$. Y la segunda razón tendría que ver con la necesidad de comparar los datos históricos con los obtenidos por la criminología contemporánea, que maneja la tasa de homicidios por 100000 habitantes para medir el promedio anual de muertes causadas por la violencia física. Pero ¿es acertado centrar el análisis de la evolución de la criminalidad exclusivamente en el indicador del homicidio? La respuesta es que resulta cuestionable que las investigaciones centradas en el paradigma cuantitativo convirtieran al homicidio en el indicador confiable para medir la violencia interpersonal y que fuera el delito que caracterizara la criminalidad histórica. En primer lugar, porque enmascara otras formas de violencia; y, en segundo lugar, porque margina otras tipologías delictivas así concebidas también por la sociedad medieval y moderna.

En relación con el primer cuestionamiento hay que señalar que centrar la mirada en el homicidio enmascara otras formas de violencia que resultan unos indicadores más precisos para tomar conciencia de su dimensión real en la vida cotidiana de la sociedad medieval y moderna, como pueden ser las amenazas, las agresiones o los asaltos. Un ejemplo es el estudio de A.J. Finch sobre la jurisdicción eclesiástica de la oficialidad de Cerisy-la-Foret entre 1314-1486, que contaba con una población aproximada de unos 6300 habitantes. En ella documentó la presencia de 336 casos de violencia (agresiones físicas), 374 casos de fornicación, 169 de adulterio, 43 de blasfemia y ocho de violación. Del análisis de los 336 casos de violencia concluyó que la práctica totalidad de ellos fueron de naturaleza leve y que estuvieron lejos de significar una amenaza para la vida, pues la mayoría de los enfrentamientos se realizaron sin armas. En consecuencia, las víctimas resultaron golpeadas con puños y pies, mordidas, arañadas, etc.; es decir, sufrieron heridas de menor consideración. No obstante, cuando las armas hicieron acto de presencia se emplearon con la finalidad de intimidar al adversario o para golpearlo con la parte plana del

89 «La delincuencia a fines de la Edad Media. Un balance historiográfico». Historia. Instituciones. Documentos, 20 (1993), p. 237.

${ }^{90}$ L. STONE, «Interpersonal violence», p. 23. 
cuchillo o de la espada y no tanto para acabar con su vida ${ }^{91}$. Jacques Chiffoleau ya había demostrado en su estudio sobre la violencia cotidiana en Avignon durante el siglo XIV que los enfrentamientos eran cuerpo a cuerpo, tirándose del cabello, dándose patadas, mordiéndose..., y con limitado empleo de armas blancas, como cuando intervenía un carnicero, por ejemplo. En este contexto «les morts ne sont préméditées; ce sont des accidents ${ }^{92}$. Muertes accidentales, pero también como consecuencia de una mala resolución de las heridas debido al escaso desarrollo de la medicina, como se comprueba en el caso de Artois analizado por Robert Muchembled. De las 2859 muertes ocasionadas entre 1400 y 1660, el 9\% fueron in situ, el 29\% en las horas siguientes y cerca de un 35\% días después, más de ocho, como consecuencia de la infección de las heridas ${ }^{93}$.

Si además de estas otras formas de violencia no mortales se tiene en cuenta también la verbal (las palabras trasmiten agresividad y hieren), como Tomás A. Mantecón en su estudio sobre Cantabria, se observa lo siguiente: al mismo tiempo que a lo largo del siglo XVII fue decreciendo la violencia homicida, las otras formas de violencia (amenazas, agresiones, injurias), por el contrario, se incrementaron hasta la primera mitad del siglo XviII. Es decir, no hubo una involución de la violencia frente al robo. Es más, a comienzos del siglo XIX se produjo un nuevo repunte de los índices de violencia homicida y de las agresiones como consecuencia de una difícil coyuntura ligada a malas cosechas y a la ocupación francesa. En definitiva, si el estudio se hubiera centrado exclusivamente en el homicidio se habría podido constatar su declive, pero no se habría comprobado que lo que realmente ocurrió es que se produjo una trasferencia de la violencia homicida hacia otras formas de violencia interpersonal. Se había civilizado la manifestación extrema de la violencia, pues a finales del Antiguo Régimen ya no era necesario «matar o herir al adversario para doblegar las voluntades o para inhibir comportamientos, las amenazas, los insultos o las murmuraciones podían servir en la mayor parte de los casos para lograr esos propósitos ${ }^{94}$.

Centrar el análisis de la modernización de la criminalidad en el indicador del homicidio margina, como se ha advertido, otras tipologías delictivas que para la sociedad medieval y moderna causaron mayor impacto y alarma social. Es decir, la atención sobre los delitos violentos proporciona una imagen distorsionada de la naturaleza de la criminalidad real en las sociedades preindustriales. Tradicionalmente se recurre a una clasificación tripartita de la delincuencia que supone la existencia de delitos contra las personas, contra la propiedad y contra la moral. Pues bien, fuera de esa interpretación del proceso de modernización de la criminalidad quedan los

91 "The nature of violence in the Middle Ages: an alternative perspective». Historical Research, vol. LXx, n. 173 (1997), pp. 249-268.

92 «La violence au quotidien», p. 354. Esta idea la expresa tambié Valérie Toureille en los siguientes términos: «Les blessures sont parfois graves mais on en meurt rarement (il s'agit alors de rixes-homicides)", Crime et châtiment au Moyen Âge, p. 44.

93 "Anthropologie de la violence dans la France moderne ( $\mathrm{Xv}^{\mathrm{e}}-\mathrm{XVIII}{ }^{\mathrm{e}}$ siècle)». Revue de Synthèse, IV ${ }^{e}$ S., n. ${ }^{\circ} 1$ (1987), p. 43.

94 «El peso de la infrajudicialidad», p. 65. 
delitos contra la moral (adulterio, sodomía, prostitución, incesto...). Dentro de ellos también suelen incluirse las transgresiones relacionadas con la ortodoxia religiosa (herejía, brujería, blasfemia....). ¿Qué pasa con estos delitos en ese diseño evolutivo de larga duración de la criminalidad? Este planteamiento de conceder a la violencia $y$, subsidiariamente, al robo ${ }^{95}$ todo el protagonismo parece olvidar que, por ejemplo, para la sociedad y la legislación medieval era más grave un adulterio cometido por una mujer que su homicidio a manos de su marido, que se consideraba justificado. Si no se atiende a lo que en cada momento histórico se consideraba delito se incurre en errores de apreciación y se pasan por alto transgresiones que para el período medieval fueron tipificadas de muy graves o "atroces» y reprimidas con severidad. En este sentido se puede mencionar el horror que las autoridades mostraron ante el pecado nefando y la terrible condena de muerte en la hoguera que se reservaba para aquéllos que incurrieran en semejante comportamiento. La mayor trascendencia de un delito para la sociedad medieval estaba en buena medida en relación con el pecado. Un ejemplo de la construcción jurídica del concepto de crimen-pecado a partir del siglo XIII es la realizada en las Partidas de Alfonso X el Sabio y estudiada por Alejandro Morín ${ }^{96}$.

\subsection{Mundo urbano vs. MUndo RURAL: Diferentes Contextos Socioeconó- MICOS, PERO ¿TAMBIÉN DELICTIVOS?}

Una investigación especialmente interesante para validar o refutar la hipótesis "de la violence au vol» (modelo normando) a partir fuentes masivas susceptibles de ser tratadas mediante métodos cuantitativos fue la realizada por los profesores daneses Jens C. Johansen y Henrik Stevnsbog ${ }^{97}$. Analizaron un volumen total de 16809 procesos correspondientes a la Dinamarca de los siglos XVII y XVIII, y pertenecientes a dos realidades geográficas y económicas diferentes: la localidad comercial de Elseneur y la isla de Falster, cuya economía se orientaba hacia el sector primario, concretamente a la pesca y a la agricultura. Para la explotación cuantitativa de ese ingente volumen documental recurrieron al método puesto a punto por Gustav Henningsen y Jaime Contreras en su análisis de las 44000 relaciones de causas que llegaron al tribunal de la Inquisición española en el período 1540-170098,

${ }^{95}$ Para Valérie Toureille en la Edad Media hubo una «trilogie criminelle: le vol, le viol et le meurtre». No obstante, a continuación señala que la Edad Media "a connu beaucoup d'autres crimes», como la herejía, la traición, la lesa majestad, el adulterio, la bigamia o el aborto que "occupent une place importante»; vid. Crime et châtiment au Moyen Âge, pp. 43 y 63, respectivamente.

${ }^{96}$ Pecado y delito en la Edad Media: estudio de una relación a partir de la obra jurídica de Alfonso el Sabio. Córdoba, Del Copista, 2009.

97 «Hasard ou myopie», pp. 601-624.

${ }^{98}$ G. Henningsen, «El "Banco de datos" del Santo Oficio. Las relaciones de causas de la Inquisición española (1500-1700)». Boletín de la Real Academia de la Historia, n. ${ }^{\circ} 74$ (1977), pp. $547-$ 570; J. Contreras, El Santo Oficio de la Inquisición en Galicia. Madrid, Akal, 1982. 
aunque mejorándolo. El resultado de la investigación arrojó las siguientes conclusiones. En primer lugar, la primera parte de la hipótesis de Boutelet parecía confirmarse: «Tendence à la diminution des affaires de violence du Xvıre au XVIIIe siècles». Ahora bien, en el caso de la localidad de Elseneur eso no significaba que se produjera al mismo tiempo un incremento de los «affaires de vol». Por el contrario, en la isla de Falster sí se comprobaba ese aumento pronunciado de los robos a partir de comienzos del siglo XVIII. En segundo lugar, cuando los datos estadísticos pasaban a ser más fiables, esto es, a partir del siglo XIX, se podía comprobar el incremento del porcentaje de robos, confirmándose la segunda parte de la hipótesis «de la violence au vol». Así, para el período de 1841-1855 el porcentaje fue el siguiente: 7\% de «affaires de violence» frente a un $93 \%$ de «affaires de vol».

En consecuencia, la hipótesis lanzada por B. Boutelet parecía, a priori, quedar confirmada en sus dos aspectos: de un lado, disminuyeron los delitos violentos y, de otro, se incrementaron los patrimoniales. Sin embargo, la evolución se había producido con diferencias regionales, a diferentes ritmos y según diferentes modalidades. En el caso de Falster, y su cambio de tendencia anterior a Elseneur, pudo deberse a una situación agrícola complicada ${ }^{99}$. En definitiva, el cambio de tendencia no sólo adoptaba variaciones nacionales, sino también regionales, y, como ya había avanzado la historiadora gala Nicole Castan, la relación violencia/robo sufría flujos y reflujos a lo largo de los siglos ${ }^{100}$. La disminución de la violencia no fue un proceso lineal, ni constante ${ }^{101}$.

Este estudio de Jens C. Johansen y Henrik Stevnsbog incidía en un aspecto puesto de manifiesto, entre otros, por Michael Weisser: la existencia de una dicotomía criminal campo-ciudad a lo largo de la Edad Moderna y surgida a finales de la Edad Media, según la cual el mundo urbano presentaba un perfil de mayor violencia, mientras que el rural mostraba una mayor presencia de delitos contra el patrimonio debido al diferente grado de desarrollo socioeconómico ${ }^{102}$. Igualmente existían diferencias entre ambos mundos en la tipología de lo que se sustraía: en el rural eran, fundamentalmente, artículos relacionados con la subsistencia e implicaban a

99 «Hasard ou myopie», pp. 604-611 y 611-613.

100 «Bilan de l'apport de la recherche historique à la connaisance de la criminalité et de la justice pénale», en La recherche historique sur la criminalité et la justice pénale, Strasbourg, Conseil d'Europe, 1984, p. 14.

${ }^{101}$ Es más, como puso de manifiesto Robert Muchembled, entre el siglo xv y el xvir la agresividad se incrementaba en la estación cálida del año, en los días festivos y en las tabernas. Es decir, la violencia variaba a lo largo del año y se concentraba en unas fechas, circunstancias y lugares determinados, en el marco de la sociabilidad cotidiana, que estaban relacionados con el ocio, la festividad y la competencia amorosa. La violence au village. Sociabilité et comportaments populaires en Artois de XVe au XVII e siècle. Turnhout, Brepols, 1989.

102 Criminalita e repressione nell'Europa Moderna. Bologna, Il Mulino, 1989 (1979), pp. 45-48. M.T. Lorcin también había comprobado que los atentados contra la propiedad dominan frente a la violencia en el campo, «Les paysans et la justice dans la región lyonnaise aux XIV et $\mathrm{xv}^{\mathrm{e}}$ siècles». Le Moyen Âge, t. 74 (1968), pp. 269-300. 
trabajadores jornaleros o estacionales, mientras que en las ciudades eran artículos de lujo. Pero ¿hasta qué punto esta consideración es cierta?

En el mundo urbano, como afirma Jacques Chiffoleau, sí estaba muy presente el fraude en relación con las actividades comerciales y artesanales que acogía, suponiendo hasta el $24.51 \%$ de las condenas en Avignon durante el siglo XIV ${ }^{103}$. Igualmente, como se ha señalado, no todos los archivos judiciales muestran la misma realidad criminal y en el caso de los registros del Châtelet de París analizados por Bronislaw Geremek, el robo emerge como el delito predominante en ese mismo siglo XIV ${ }^{104}$. Por otra parte, no todos los investigadores están de acuerdo con la afirmación de que las ciudades fueran más criminógenas que el campo. Por ejemplo, James B. Given para la Inglaterra del siglo XIII observa unas tasas de homicidio inferiores en Londres que en las zonas rurales ${ }^{105}$; o Robert Muchembled, quien sostiene, a partir de sus trabajos sobre el condado de Artois durante los siglos XV-XVII, que la violencia homicida se encontraba más vigilada en las ciudades como consecuencia del sistema de control social articulado para mantener la paz y el orden ${ }^{106}$. En otras palabras, ¿se ha minusvalorado la importancia de los delitos contra el patrimonio en el mundo urbano frente al impacto de la violencia de sangre y viceversa en el mundo rural?

\subsection{LA MirADA CUALITATIVA: EL GIRO CULTURAL}

La incidencia de la postmodernidad en la historiografía a partir de finales de la década de los 70 de la pasada centuria trajo consigo un cambio de paradigma epistemológico. Así, el análisis e interpretación de los fenómenos históricos desde la perspectiva estructural, desde los grandes metarrelatos clásicos, desde la idea de una racionalidad única... y desde la prevalencia de la cuantificación (historia serial) se trasladó hacia el enfoque antropológico, el microanálisis, la narrativa y la recuperación del sujeto ${ }^{107}$. Es lo que se ha denominado el «giro cultural en la investigación histórica» ${ }^{108}$. A este cambio contribuirían, entre otros, filósofos como Michel Foucault, antropólogos como Cliford Geertz, sociólogos como Norbert Elias, historiadores como Natalie Z. Davis, Carlo M. Ginzburg o Robert Chartier.

Estos cambios en el paradigma historiográfico, obviamente, también repercutieron en una revisión crítica de la perspectiva cuantitativa de análisis de la crimi-

103 «La violence au quotidien», pp. 343 y 363.

${ }^{104}$ Les mariginaux parisiens aux XIVe et XVe siècles. Paris, Falammarion, 1976.

105 Society and homicide in Thirteenth century England, pp. 174-175.

106 La violence au village...

107 C. Barros (coord.), Historia a debate. II. Retorno del sujeto. Santiago de Compostela, 1995.

108 K. Donald, «El giro cultural en la investigación histórica», en I. Olábarri \& F. CasPISTEGUi (coords.), La «nueva» Historia cultural, la influencia del postestructuralismo y el auge de la interdisciplinariedad, Madrid, Universidad Complutense, 1996, pp. 35-48. 
nalidad y se la enfrentó al contraste de la cualitativa; es decir, se produjo, igualmente, un giro cultural en los estudios sobre la criminalidad. Ya había señalado Jacques Chiffoleau que «seule une étude qualitative très minutieuse, à partir des procès par exemple, permettrait d'interpréter ces "carectères originaux" de la criminalité entre le XIVe et le XVIIIe siècle»" ${ }^{109}$. Lo antropológico permite acceder al funcionamiento de las sociedades a través del estudio de sus actitudes y comportamientos ante la vida y la muerte, con sus ritos y normas, lo que permite revelar las estructuras elementales y complejas de la actividad humana. Por ello, Robert Muchembled diría en relación con la violencia: «Pour être saisie de manière plus complète et plus globale, la violence doit être l'objet d'une véritable anthropologie» ${ }^{10}$.

El giro cultural no sólo incidió en la renovación del análisis histórico, sino también en la incorporación de una multitud de racionalidades con su propio discurso en la explicación del fenómeno criminal. Surgirían así estudios sobre las diversas manifestaciones de la violencia, sobre las prácticas judiciales, sobre el control social formal (el Estado y las instituciones judiciales y policiales) e informal (la comunidad, por ejemplo, a través de las cencerradas), sobre el castigo...; en definitiva, el interés se extendería por nuevas y diversas temáticas hasta el punto de que hoy son necesarios estudios que las sistematicen ${ }^{111}$. Y, por último, el giro cultural trajo consigo una ampliación del espectro de las fuentes documentales, más allá de

109 «La violence au quotidien", pp. 332 y 346.

110 «Anthropologie de la violence», p. 32. Un ejemplo de un estudio realizado desde la perspectiva de la antropología histórica es el David Nirenberg sobre las funciones de la violencia en la sociedad medieval de Espańa y del midi francés. Llega a la conclusión de que la violencia entre la mayoría cristiana y la minoría judía era sistémica, de carácter sagrado y recurrente en momentos como la Semana Santa, pero también como consecuencia del miedo a la Peste Negra de 1348 y al «otro» judío en 1391. Communities of violence. Persecution of minorities in the Middle Age. Princeton University Press, 1996. Igualmente, Flocel Sabaté estudia el comportamiento violento en la Cataluña de finales de la Edad Media como un medio de intimidar al contrario, incluidos los judíos, ya fuera en su persona o bines; vid. "Orden y desorden. La violencia en la cotidianidad bajomedieval catalana». Aragón en la Edad Media, n. ${ }^{\circ}$ 14-15, fascículo 2 (1999), pp. 1389-1408, en especial p. 1399 y ss.

111 Sobre todas las posibilidades abiertas en los estudios de la criminalidad y del sistema penal a partir de esta nueva orientación historiográfica puede consultarse el completo estado de la cuestión realizado por F. SEgURA URRA, «Raíces historiográficas y actualidad de la historia de la justicia y el crimen en la Baja Edad Media». Anuario de Historia del Derecho Español, n. ${ }^{\circ} 73$ (2003), pp. 577-678, especialmente a partir de la página 616. 
los procesos judiciales ${ }^{12}$, abarcando desde los registros notariales ${ }^{113}$ hasta la iconografía $^{114}$, pasando por la literatura ${ }^{115}$.

Desde este nuevo paradigma cultural dos han sido las teorías que más han contribuido al debate sobre el declive de la violencia desde la Edad Media a la Contemporánea: el proceso de civilización de Norbert Elias, que suponía la moralización de las costumbres y la transformación interna de los comportamientos; y el disciplinamiento o control social ejercido por las autoridades sobre comportamientos considerados antisociales (sozialdisciplinierung). De esta forma se construyó una interacción entre la metodología cuantitativa, desde la perspectiva de la historia social, y la cualitativa, desde la perspectiva de la historia cultural.

En 1939 el sociólogo germano Norbert Elias enunciaba su teoría sobre el proceso de civilización para explicar cómo se emprendería la domesticación de los instintos, emociones y modales de los individuos en el transcurso de los siglos que van desde el Humanismo a la Ilustración, afectando en primer lugar a los estratos superiores de la sociedad, desde donde poco a poco se difundiría al resto. Según Elias, a partir del siglo XVI se originaría una evolución en la sociedad europea desde los postulados feudales, caracterizados por el incivismo (comportamientos y sensibilidades bárbaras, impulsivas y emotivas) y la sociabilidad de la violencia ejercida de forma desinhibida, hasta otros modos de vida más modernos, contenidos y civilizados (cortesía, moralidad, alfabetización...) ${ }^{116}$. Así, la nobleza guerrera transformaría su comportamiento agresivo en cortés a partir de ese siglo $\mathrm{XVI}^{117}$. El nuevo hombre moderno ${ }^{118}$, frente al medieval, se caracterizaría por un autocontrol de los impulsos y de las emociones como consecuencia de la interiorización de los nuevos

$112 \mathrm{Al}$ respecto señala Xavier Rousseaux: «Une des difficultés de l'histoire médiévale est la mise en contexte des sources. Habitué à faire son miel de toute fleur, le médiéviste tend à construire son tableau du paysage criminel à partir de sources au statut varié: texte normatif, récit hagiographique, acte judiciaire, registre du Parlement, fragment d'écrou, compte de frais de justice, registre de cour locale, procès exceptionnellement conservé»; vid. "Historiographie du crime et de la justice criminelle dans l'espace français (1990-2005). Partie I», párrafo 36, consultado el 30 de septiembre de 2016, http://chs.revues.org/203.

113 A. Soman, «L'infrajustice à Paris d'après les archives notariales». Histoire, Économie et Société, 3 (1982), pp. 369-376.

${ }^{114}$ L. Puppi, Les supplices dans l'art. Cérémonial des exécutions capitales et iconographie du martyre dans l'art européen du XII e au XIXe siècle. Paris, Larouse, 1991 (Milán, 1990); R. JACOB, Images de la justice. Essai sur l'iconographie judiciaire du Moyen Âge à l'Âge classique. Paris, Le Léopard d'Or, 1994. En el caso español recientemente se ha abordado esta cuestión: P. RodríGuez BarRaL, La justicia del más allá. Iconografía en la Corona de Aragón en la Baja Edad Media. València, Universitat de València, 2007 y Y. Ruiz Gallegos, Aproximación al estudio del juicio final y del juicio del alma en la Corona de Castilla en la Baja Edad Media. Bilbao, Universidad del País Vasco, 2008.

115 Un ejemplo sería B. Geremek, La estirpe de Caín. La imagen de los vagabundos y de los pobres en la literatura europea de los siglos XV al XVII. Madrid, Mondadori, 1991.

${ }^{116}$ El proceso de la civilización. Investigaciones sociogenéticas y psicogenéticas. México, Fondo de Cultura Económica, 1988 (1939).

117 B. Castiglione, El cortesano. Madrid, Alianza Editorial, 2008.

118 R. Muchembled, L'invention de l'homme moderne. Sensibilités, moeurs et comportements collectifs sous l'Ancien Régime. Paris, Fayard, 1988. 
valores civilizados, la paz entre ellos. Elias consideró que ese incorporar los valores civilizados en las formas de ser, de actuar o de sentir de los individuos se había alcanzado gracias a un proceso de carácter psicogenético. A su vez, ese autocontrol, expresado en un menor recurso a la violencia, se complementaría con la pacificación de la sociedad a través de la asunción del monopolio de la violencia por parte del Estado como consecuencia de un proceso, en este caso, de carácter sociogenético $^{119}$. Por el contrario, desde la perspectiva del disciplinamiento social, el autocontrol vendría inducido desde el exterior a través de la coerción y la disciplina ejercidas por las estructuras políticas y los mecanismos de control del Estado moderno.

El argumento de Elias para explicar el declive de la violencia de raíz medieval a partir del siglo XVI, gracias a la interiorización de los valores civilizados y a la domesticación de los impulsos, gozó de gran éxito entre los investigadores. Un ejemplo es Ted R. Gurr, quien en su estudio clásico sobre el declive del homicidio en Inglaterra apuntó que se debía a un aumento de la sensibilización frente al uso de la violencia («sensitization to violence») ${ }^{120}$. Pero esta teoría de Elias también conoció la crítica, como la realizada por Claude Gauvard. Esta historiadora gala señaló que Elias pintó un cuadro ingenuo y simplista de la Edad Media y que, al igual que Johan Huizinga y su El otoño de la Edad Media (1919), había incurrido en el mito de una Edad Media salvaje y oscura ${ }^{121}$. No tuvo en cuenta que el comportamiento violento medieval no siempre estaba necesariamente relacionado con un descontrol de las emociones, de la agresividad, sino que respondía a mecanismos ritualizados de resolución de conflictos ligados a la existencia de códigos de honor ${ }^{122}$. Además, también se ha evidenciado la inconsistencia de la teoría del «proceso de civilización». Historiadores como Xavier Rousseaux, Bernard Dauven y Aude Musin han demostrado en su estudio sobre el municipio belga de Nivelles entre 1371 y 1696 que el decrecimiento del homicidio no fue regular ni lineal, sino que mostraba una evolución de dientes de sierra, con un incremento importante entre 1581 y $1641^{123}$. Es más, durante el período de las guerras de religión Europa conoció un retroceso en el declinar secular de la violencia homicida.

119 El concepto de monopolio de la violencia ejercido por el Estado fue desarrollado por M. Weber, Economía y sociedad. Esbozo de sociología comprensiva. Madrid, FEC, 2002 (1922), capítulo IX, titulado «Sociología de la dominación».

120 «Historical trends in violent crime», p. 300.

121 «De grace especial», vol. II, p. 944.

${ }^{122}$ A este respecto P. Schuster relata un ejemplo del siglo xv acaecido en el mercado del pescado de Basilea. Allí, una noche se enfrentaron a cuchilladas dos personas para solucionar sus diferencias, que venían de antes y que había originado una relación conflictiva entre ambas partes. También alude a la existencia de terceras personas que se interponían entre las partes enfrentadas con objeto de sosegar y apaciguar los ánimos; Der gelobte Frieden. Täter, Opfer und Herrschaft im spätmittelalterlichen Konstanz, Konstanz, 1995, pp. 98-104.

123 «Civilisation des moeurs et/ou disciplinarisation sociale?», p. 284. 
Pero quien tal vez encarne una de las principales voces críticas es Gerd Schwerhoff ${ }^{124}$. Para este profesor de la Universidad de Dresden la teoría de Elias es frágil porque planteó un diseño teleológico de una evolución de progreso sucesiva, cuando los movimientos tendentes hacia ese "proceso de civilización» eran involuntarios e imprevistos, con irregularidades en su evolución ${ }^{125}$. Otra cuestión problemática es que Elias basaba su "proceso de civilización» en buena medida en el modelo cortesano francés y no resulta exportable a otras áreas geográficas. Además, si se conecta esta teoría con los resultados empíricos de la estadística criminal y de la demografía, ambos de una validez cuestionable, el resultado no es satisfactorio porque no ofrece una explicación uniforme para toda Europa (en el área mediterránea, por ejemplo, la cultura de la violencia pervivió por más tiempo que en el resto del continente), ni tampoco para las diversas regiones de un mismo reino. Por todo ello, Gerd Schwerhoff sentencia que el paradigma de Elias sobre procesos de cambio macrohistóricos no permite abordar las causas que justifican la disminución de los índices de violencia homicida, que es lo único demostrable que aconteció entre los siglos XVII y XVIII.

Junto con la teoría de Elias, también las instituciones de control social de carácter disciplinario expuestas por Weber, Gerhard Oestreich o Foucault, como mecanismos de dominación que contribuyeron al proceso de formación y de perpetuación del Estado, han servido para explicar el declinar multisecular de la violencia homicida. Estos mecanismos de dominación poseen un carácter simbólico, territorial y político. Simbólico porque el castigo y la gracia que el poder del Estado ejerce a través del sistema penal sirven para que la ciudadanía sea consciente de que existe una autoridad superior, el soberano, que ostenta el derecho. Territorial porque demarca el ámbito espacial de ejercicio de esa soberanía. Político porque con el control de la justicia penal el Estado se hace con el monopolio de la violencia y convierte al monarca en el único recurso para alcanzar la paz y el orden social ${ }^{126}$.

124 "Criminalized violence and the process of civilisation: a reappraisal». Crime, Histoire \& Sociétés / Crime, History \& Societes, vol. 6, n. ${ }^{\circ} 2$ (2002), pp. 103-126. Con anterioridad ya había abordado esta crítica en "Zivilisationsprozess und Geschichtswissenschaft. Norbert Elias Forschungsparadigma in historischer Sicht». Historische Zeitschrift, 266 (1998), pp. 561-605. Junto con Schwerhoff otros críticos han sido M. Dinges, «Formenwandel der Gewalt in der Neuzeit. Zur Kritik der Zivilisations theorie von Norbert Elias", en R.P. Sieferle \& H. Breuninger (eds.), Kulturen der Gewalt. Ritualisierung und Sym bolisierung von Gewalt in der Geschichte, Frankfurt, 1998, pp. 171-194.

125 Este argumento ya había sido avanzado por Rolf Peter Sieferle, al acusar a Elias de realizar una narrativa simplista y lineal en su introducción a R.P. Sieferle \& H. Breuninger (eds.), Kulyuren der Gewalt. Ritualisierung und Symbolisierung, pp. 14-15. Pieter Spierenburg señala que entre los historiadores alemanes de la criminalidad se ha convertido en un lugar común criticar la teoría de Elias, «Violence and the civilizing process», p. 90. Sobre la historiografía alemana y la historia de la criminalidad G. Schwerhoff, "La storia della criminalità nel tardo medioevo e nella prima età moderna. Il "ritardo" di un settore della ricerca tedesca». Annali dell'Istituto Storico italo-germanico in Trento, 24 (1999), pp. 573-630.

126 X. Rousseaux, "Crime, Justice and Society in Medieval and Early Modern Times: Thirty Years of Crime and Criminal Justice History. A tribute to Herman Diederiks». Crime, His- 
En los años 60 del siglo xx se incidiría precisamente en el concepto de «disciplinamiento social» (sozialdisziplinierung) de la mano de Gerhard Oestreich ${ }^{127}$ al estudiar los cambios operados por las instituciones y poderes estatales en la sociedad alemana de época moderna mediante «acciones disciplinarias de control y moralización» al objeto de moldear su comportamiento para asegurar la paz y el orden social; al mismo tiempo que creaban vínculos que sirvieran para que los súbditos se identificaran afectivamente con su proyecto político ${ }^{128}$. El concepto de «disciplinamiento social» que puso en marcha la historiografía alemana se completó mediante el de "confesionalización" (konfessionalisierung). Las Iglesias o confesiones colaborarían estrechamente con los Estados en el disciplinamiento de los ciudadanos. Se identificó el delito y el pecado, uniendo los intereses del Estado y de las Iglesias, quienes proporcionaban el argumento ideológico desde el púlpito para que la comunidad rechazara los comportamientos juzgados como desviados, especialmente los relacionados con la sexualidad, el juego, el alcohol, la blasfemia..., el escándalo público ${ }^{129}$. Desde esta perspectiva se ha estudiado también la administración de justicia, comprobándose cómo en los tiempos modernos la resolución de conflictos entre partes no se resolvía de forma interpersonal y privada como en la Edad Media, sino que se recurría al Estado como garante del orden social y dirimente de las partes enfrentadas ${ }^{130}$.

Algunos problemas con esta teoría son, por ejemplo, que el control ejercido por el Estado moderno como argumento explicativo de la emergencia de una sociedad menos violenta no siempre es cierto, porque acontece tanto en monarquías absolutas como en otras carentes de estructuras de poder centralizadas ${ }^{131}$. Igualmente,

toire \& Sociétés / Crime, History \& Societies, vol. 1, n. 1 (1997), pp. 87-118, consultada la versión online el 7 de marzo de 2014, párrafo 83: http://chs.revues.org/1034.

127 Un recorrido historiográfico sobre este concepto en H. Schilling, «El disciplinamiento social en la Edad Moderna: propuesta de indagación interdisciplinar y comparativa», en J.I. Fortéa, J.E. Gelabert \& T.A. Mantecón (eds.), Furor et rabies. Violencia, conflicto y marginación en la Edad Moderna, Santander, 2002, pp. 17-45. Este texto fue previamente publicado en H. Roodenburg \& P. Spierenburg (eds.), Social control in Europe. Vol. 1, 1500-1800. Columbus, The Ohio State University Press, 2004, pp. 25-36. Resulta interesante en este mismo volumen la introducción de Pieter Spierenburg sobre el control social en la Historia, «Social control and History: an introduction", pp. 1-24.

128 T.A. Mantecón, «Formas de disciplinamiento social, perspectivas históricas». Revista de Historia Social y de las Mentalidades, vol. 14, n. 2 (2010), p. 265.

129 W. Reinhard, «Disciplinamento sociale, confessionalizazione, modernizzazione. Un discorso storiografico", en C. Penuti (ed.), Disciplina dell'anima, disciplina del corpo e disciplina della societè tra medievo ed età moderna, Bologna, Il Mulino,1994, pp. 101-123.

${ }^{130}$ En España uno de los historiadores que ha seguido esta línea de investigación ha sido Tomás A. Mantecón en estudios como Conflictividad y disciplinamiento social en la Cantabria rural del Antiguo Régimen. Santander, Universidad de Cantabria y Fundación Marcelino Botín, 1997. Más recientemente Mikel Berraondo Piudo ha abordado cuestiones como el «disciplinamiento social», la "confesionalización", la representación de la violencia, etc. en su tesis doctoral titulada La violencia interpersonal en la Navarra moderna (siglos XVI-XVII). Pamplona, Universidad de Navarra, 2012.

131 R. Muchembled, Una historia de la violencia, pp. 39 y 44. 
los procesos de control y de moralización de los comportamientos no comenzaron con el Estado moderno centralizado ni con las corrientes reformadoras (protestante y católica). Ya en el siglo xv las élites urbanas comenzaron a desarrollar procesos de regulación de los comportamientos de sus administrados, dotándose de instrumentos de buen gobierno para asegurar el orden y la paz, como el control de armas, el buscar acuerdos entre las partes enfrentadas, el destierro temporal de las personas conflictivas, el impedir el asentamiento de vagabundos, el velar por la higiene pública... ${ }^{132}$. Para Xavier Rousseaux, Bernard Dauven y Aude Musin este proceso surgiría como consecuencia de la gentrificación de las élites urbanas. Éstas tendrían un mayor peso en la construcción del hombre moderno, como motor del cambio de los comportamientos y de las formas de sociabilidad, que la nobleza rural según pensaba Norbert Elias ${ }^{133}$.

Uno de los renovadores del concepto de disciplinamiento ha sido Michel Foucault. Para este filósofo galo las instituciones especializadas (la escuela, el hospital, el cuartel o la cárcel) desarrollaron un proyecto de control social, a través de sus propios agentes (maestros, médicos, policías...), consistente en aplicar un tratamiento disciplinario específico para cada individuo (microfísica del poder) con el fin de reprimir los comportamientos considerados antisociales y de reducir a la normalidad y a la utilidad social los cuerpos de los ciudadanos desviados ${ }^{134}$. Foucault también reflexionó sobre la causalidad que posibilitaría el paso de una "criminalidad de sangre a una delincuencia de fraude» y concluyó que se encontraba en la suma de factores culturales y socioeconómicos: «El desarrollo de la producción, el aumento de las riquezas, una valoración jurídica y más intensa de las relaciones de propiedad, unos métodos de vigilancia más rigurosos, una división en zonas más ceñida de la población, unas técnicas más afinadas de localización, de captura y de información $»^{135}$.

A Foucault se le ha criticado, entre otras cosas, situar en el Estado liberal el origen de los cambios en la justicia penal, cuando ya se habían producido con anterioridad; presentar el ejercicio del poder de forma mecanicista y olvidarse del contexto; plantear el disciplinamiento como consecuencia de un poder exterior y

132 Para el caso francés y alemán véase, por ejemplo, K. HärTER, «Disciplinamento sociale e ordinanze di polizia nella prima età moderna», en P. ProDi (ed.), Disciplina dell'anima, disciplina del corpo e disciplina della societè..., pp. 635-658. Para el inglés P.C. MAdDERn, Violence and social order: East Anglia, 1422-1442. Oxford, Clarendon Press, 1992. Y para el español I. BAzÁN, «La criminalización de la vida cotidiana. Articulación del orden público y del control social de las conductas", en J.M. ${ }^{2}$ Imízcoz (coord.), La vida cotidiana en Vitoria en la Edad Moderna y Contemporánea, San Sebastián, Txertoa, 1995, pp. 113-168; ibidem, "Control social y control penal. La formación de una política de criminalización y de moralización de los comportamientos en las ciudades de la España medieval», en S. Castillo y P. Oliver (coords.), Las figuras del desorden. Heterodoxos, proscritos y marginados, Siglo XXI, Madrid, 2006, pp. 255-283; R. IzQuierdo Benito, Un espacio desordenado. Toledo a fines de la Edad Media. Toledo, Universidad de Castilla-La Mancha, 1996.

133 "Civilisation des moeurs et/ou disciplinarisation sociale?», p. 308.

134 Vigilar y castigar. Nacimiento de la prisión. Buenos Aires, Siglo XXI, 2002 (1975).

135 M. Foucault, Vigilar y castigar, pp. 81-82. 
demiúrgico; considerar que los procesos de cambio cultural venían provocados por las instituciones responsables de las acciones disciplinarias y no visualizar la capacidad de los individuos y de las comunidades para eludir la "disciplina» y para generar una cultura que influyera en el cambio social. Es decir, Foucault centró su análisis más en el cambio generado desde «arriba», a través del monopolio del control social, y postergó la existencia de un control social desde «abajo» establecido por las comunidades con sus propias reglas, como se observa en casos como el de las cencerradas. No consideró que en la interacción de ambos procesos estaba la clave $e^{136}$.

En definitiva, se puede concluir con Xavier Rousseaux, Bernard Dauven y Aude Musin que ambas teorías, la del proceso de civilización y la del disciplinamiento social, «sont bien moins antagonistes qu'il n'y paraît» a la hora de explicar el declinar de la violencia homicida a partir de la Edad Media y que en la interacción de ambas se encontraría su fortaleza ${ }^{137}$. En este sentido podrían traerse a colación las investigaciones de autores como Pieter Spirenburg o Robert Muchembled. Para el primero, cuyas investigaciones se centran en el estudio de la evolución de la violencia en Amsterdam desde el siglo XV al xIx, lo que habría acontecido no fue una disminución real de la violencia, sino que seguiría existiendo, aunque contenida, ya que el factor civilizatorio habría contribuido al control de las emociones agresivas. Pero añade que junto con ese factor también coadyuvaría la acción de la institución judicial ${ }^{138}$. Para Robert Muchembled, por su parte, el poder contribuiría a moralizar y a civilizar las conductas, criminalizando ciertas formas de violencia, como la popular, por considerarla ilegítima y, en este sentido, señalaba que sus niveles eran los mismos, pero controlados y perseguidos en algunas de sus manifestaciones ${ }^{139}$. Esta criminalización de ciertos comportamientos violentos (como el duelo, por ejemplo), junto con la asunción por parte del Estado del monopolio de la violencia (desarmando a la ciudadanía), con el control de poblaciones peligrosas (vagabundos, proxenetas...), con la vigilancia policial a pie de calle..., habrían contribuido a la reducción de las tasas de violencia junto con el autocontrol e interiorización de los nuevos valores por parte de los individuos.

Para explicar la disminución de los delitos de sangre y su sustitución por los de patrimonio, además de en el proceso de civilización y en el disciplinamiento

${ }^{136}$ Una reflexión crítica sobre los planteamientos de Foucault se recoge en M. Porret (ed.), L'Impossible prison. Recherches sur le système pénitentiaire au XIXe siècle. Paris, Seuil, 1980.

137 "Civilisation des moeurs et/ou disciplinarisation sociale?», p. 310.

138 «Faces of violence. Homicide trends and cultural meanings: Amsterdam, 1431-1816». Journal of Social History, 27 (1994), pp. 701-716. Recientemente ha resumido su punto de vista en "Violence and the civilizing process: does it work?». Crime, Histoire \& Sociétés / Crime, History \& Societies, vol. 5, n. 2 (2001), pp. 87-105. Spierenburg analiza la teoría de Elias bajo cuatro parámetros: 1) la fiabilidad y validez de las pruebas que ponen de manifiesto la disminución de la violencia en la larga duración. 2) La función de la violencia como medidor del nivel de autocontrol conductual. 3) La interrelación entre el cambio de las emociones humanas, especialmente por lo que a la agresividad se refiere, y el desarrollo social. 4) La nueva ola de violencia interpersonal de la sociedad occidental de finales del siglo xx.

139 «Anthropologie de la violence», pp. 48-52. 
social, también se ha puesto el acento en el paso de una mentalidad de corte medieval que privilegiaba el honor a otra de signo capitalista y más economicista. En la primera, el honor, la fama o la condición social eran los atributos y los valores más estimados, por ello los delitos se dirigían contra las personas. Por el contrario, en una sociedad capitalista eran el dinero y las relaciones comerciales los que poseían un mayor valor social y sobre los que pivotaba la organización social; por tanto, los delitos eran dirigidos contra la propiedad ${ }^{140}$. Este nuevo escenario surgido a partir de la formación de los Estados modernos y la aparición del precapitalismo ${ }^{141}$ introdujo un cambio de actitud frente a la pobreza y a la mendicidad. Durante la Edad Media existió un ethos de la pobreza que la justificaba, la santificaba y la paliaba recurriendo a la caridad y a la promesa de salvación eterna, lo que habría contenido a las masas de menesterosos de rebelarse ante su situación. Por el contrario, con el alumbramiento de la sociedad moderna precapitalista el ethos de la pobreza fue remplazado por el del trabajo y eso supuso un cambio de mentalidad frente a los pobres, que pasaron a estar sometidos a un mayor control social e ideológico, al igual que la propiedad. Las ciudades modernas se convirtieron en el refugio para una multitud de desheredados provenientes del campo que pasaron a formar una clase urbana estructuralmente empobrecida que se veía forzada, para sobrevivir, a incurrir en comportamientos en los límites de la legalidad, cuando no eran directamente delictivos ${ }^{142}$. Por ello comenzaría a ejercerse un control sobre las capas marginales y no productivas de la sociedad, criminalizándose la pobreza y planteando alternativas al sistema penal aflictivo desde criterios de utilidad, ya fuera para servir al Estado en sus empresas políticas (en galeras y en los ejércitos) o para servir a su economía, recuperándose la capacidad productiva de esos individuos mediante los encierros disciplinarios ${ }^{143}$.

Entre otros, ya habían avanzado Max Weber y E. Durkheim que la modernización, la urbanización y la industrialización afectaban al modelo de criminalidad, provocando un supuesto auge de los delitos contra la propiedad frente al crimen violento ${ }^{144}$. En otras palabras, el honor como base de la organización social medieval era desplazado por la importancia de los lazos económicos en las socieda-

${ }^{140}$ L. Stone, «Interpersonal violence», pp. 29-30. Contra estos planteamientos se ha posicionado J.A. Sharpe, «The history of violence in England: some observations». Past \& Present, n. ${ }^{\circ} 108$ (1985), p. 212.

${ }^{141}$ M.R. Weisser planteó que el inicio de estos cambios no acontecieron en el siglo XVIII, sino en el xvi, con el surgimiento de la sociedad precapitalista: Criminalita e repressione...

142 J.-P. GutTon, La société et les pauvres en Europe, XVIe-XVIIIe siècles. Paris, PUF, 1974; C. Lis \& H. Soly, Poverty and capitalism in pre-industrial Europe. Brighton, The Harvester Press, 1979; B. Geremek, La piedad y la horca. Historia de la miseria y de la caridad en Europa. Madrid, Alianza Editorial, 1989 (1. ${ }^{a}$ ed. francesa 1986); C. López Alonso, La pobreza en la España medieval: estudio histórico-social. Madrid, Ministerio de Trabajo y Seguridad Social, 1986.

143 P. Trinidad Fernández, La defensa de la sociedad: cárcel y delincuencia en España (siglos XVIII-XX). Madrid, Alianza, 1991.

144 F. Segura Urra, «Raíces historiográficas», p. 599. Este argumento es desarrollado por E. Le Roy Ladurie, «La décroissance du crime au XVIII siècle», pássim. M. Weber, Economía 
des burguesas, lo que ocasionaba un proceso de modernización de la criminalidad denominado «de la violence au vol» o como lo ha rebautizado Eva Österberg: «Del honor a la economía ${ }^{145}$. Precisamente esta historiadora de la Universidad de Upsala ha analizado los cambios que acontecen en la criminalidad en las sociedades preindustriales, pero teniendo en cuenta las circunstancias socioeconómicas, además de los cambios culturales producidos en los sistemas de valores y en las normas. Esta perspectiva holística ha sido el leitmotiv del trabajo colectivo dirigido por Laurent Mucchielli y Pieter Spierenburg a la hora de interpretar la evolución decreciente del homicidio desde la Edad Media hasta el presente, al interrogarse por las fuentes para su estudio, por las formas en las que se ha manifestado la violencia, por los factores que han contribuido a esa evolución, por los actores y sus motivaciones, por los conflictos y por las interpretaciones ${ }^{146}$.

\section{A MODO DE CONCLUSIÓN}

Resulta sumamente difícil categorizar el modelo de criminalidad de una sociedad cuando la mirada se circunscribe y privilegia una determinada conducta y transgresión, en este caso el homicidio, relegando el resto, incluidas otras formas de violencia no letal. Esto supone no tener en cuenta la jerarquía delictiva de cada momento histórico en concordancia con su escala de valores.

Más, a pesar de que se es consciente de que las sociedades preindustriales son igualmente preestadísticas; que no disponen de fuentes judiciales homogéneas y seriales que permitan la comparación entre reinos y regiones; que cuentan con una multiplicidad de jurisdicciones criminales que ocasiona, por ejemplo, una dispersión del registro de un mismo delito entre todas ellas; o que no todo conflicto se judicializa, sino que se resuelve a través de la mediación, por lo que no se encuentra registrado; todavía se insiste en la cuantificación para conocer la evolución del delito de violencia homicida desde la Edad Media al siglo xix. La limitada estadística criminal y el análisis serial sí permite acercarse sobre todo a la práctica judicial, a las características del delito registrado, a la relación entre víctima y agresor o a la respuesta social y legal frente al delito, más que establecer modelos globales de comportamiento criminal ${ }^{147}$. Sería interesante recordar las palabras de Juan Miguel Mendoza Garrido cuando dice, siguiendo a J.A. Sharpe, que la cuantificación «debe ser limitada en sus ambiciones, extremadamente cautelosa en sus métodos y presen-

y sociedad. Esbozo de sociología comprensiva. Madrid, Fondo de Cultura Económica, 2002 (1922); E. Durkheim, Las reglas del método sociológico. México, Fondo de Cultura Económica, 1986 (1895). 145 "Gender, class, and the courts: Scandinavia», p. 55.

146 Histoire de l'homicide en Europe, de la fin du Moyen Âge à nos jours. Paris, La Découvert, 2009 , p. 9.

${ }_{147}$ F. Segura, «Raíces historiográficas», p. 610. 
tar sus resultados con sumo cuidado, para concluir que no es sólo contar lo que el historiador debe hacer en los archivos judiciales» ${ }^{148}$.

Más, abordar de forma lineal la racionalización de la evolución multisecular decreciente de los delitos de sangre sin atender a los procesos de criminalización y descriminalización de los comportamientos ligados a los diversos contextos sociales, económicos y culturales conlleva problemas interpretativos. Es lo que sucede cuando se recurre exclusivamente a macroteorías sociológicas omnicomprensivas, como el "proceso de civilización» o el «disciplinamiento social», sin tener en cuenta sus limitaciones. Igualmente, en este sentido, el modelo de criminalidad medieval y su modernización está centrado en mayor medida en los resultados obtenidos a partir del mundo urbano, pero ¿qué pasa en el rural?, ¿'os datos difieren?, ¿hasta qué punto?

Más, el paradigma de la modernización de la criminalidad medieval, que presupone una reducción multisecular de la violencia homicida hasta su sustitución por los delitos contra el patrimonio a partir de los siglos XVIII/XIX y sustentado en una estadística criminal inconsistente, no puede ser certificado como un modelo teórico europeo, porque las investigaciones muestran otras realidades cronológicas, geográficas o delictivas y los argumentos sobre la incidencia de las transformaciones socioeconómicas y culturales (Estado, derecho, justicia, valores...) en el cambio no resultan universales. Es decir, disminución de la violencia interpersonal sí, pero no necesariamente como corolario un aumento de los delitos patrimoniales.

En definitiva, ¿estamos totalmente de acuerdo con la respuesta que da Xavier Rousseaux a la pregunta "Existe-t-il une criminalité d'Ancien Régime?»: «Il n'existe pas de criminalité européenne d'Ancien Régime. Si par "criminalité" on entend ce qu'appellent fréquemment les chercheurs dans le titre de leur publication, en réalité, il existe autant de criminalités que d'études différentes. Â chaque sensibilité régionale, à chaque période historique correspond une criminalité spécifique [...]. Le "crime" britannique n'est pas la "criminalità" italienne. Une histoire du mot et de ses variations reste à faire» ${ }^{149}$. Es más, como sentenciaría Félix Segura, «la definición de una criminalidad real es reconocida como labor imposible casi por unanimidad $»^{150}$.

ReCIBIDO: 3-10-2018; ACEPTADO: 19-6-2019

148 «La delincuencia a fines de la Edad Media: un balance historiográfico». Historia. Instituciones. Documentos, n. ${ }^{\circ} 20$ (1993), p. 244.

149 «Existe-t-il une criminalité d'ancien régime (XIII-XVIII ${ }^{\mathrm{e}} \mathrm{s}$.)? Réflexions sur l'histoire de la criminalité en Europe», en B. Garnot (ed.), Histoire et criminalité de l'Antiqueté au XX' siècle. Nouvelles aproches, Dijon, Éditions Universitaires de Dijon, 1992, p. 147.

150 «Raíces historiográficas», p. 606. 


\section{BIBLIOGRAFÍA CITADA}

BAILEY, Victor, «Reato, giustizia penale e autoritè in Inghileterra. Un decenio di studi storici, 19691979». Quaderni Storici, n. ${ }^{\circ} 44$ (1980), pp. 581-602.

Barros, Carlos (coord.), Historia a debate. II. Retorno del sujeto. Santiago de Compostela, 1995.

BAzÁN, Iñaki, «La criminalización de la vida cotidiana. Articulación del orden público y del control social de las conductas», en J.M. Imízcoz (coord.), La vida cotidiana en Vitoria en la Edad Moderna y Contemporánea, San Sebastián, Txertoa Argitaldaria, 1995, pp. 113-168.

BAZÁN, Iñaki, «El refugio de la delincuencia señorial. Torres y casas fuertes en el País Vasco: el ejemplo de la Torre de Berna». Sancho el Sabio. Revista de Cultura e Investigación Vasca, n. 8 (1998), pp. 23-50.

BAZÁn, Iñaki, «Mujeres, delincuencia y justicia penal en la Europa medieval. Una aproximación interpretativa", en R. CóRdoBA DE LA LLAVE (coord.), Mujer, marginación y violencia entre la Edad Media y los tiempos modernos, Córdoba, Servicio de publicaciones de la Universidad de Córdoba, 2006, pp. 29-74.

BAzÁn, Ińaki, «Control social y control penal: la formación de una política de criminalización y de moralización de los comportamientos en las ciudades de la España medieval», en S. CAsTIllo y P. Oliver (coords.), Las figuras del desorden. Heterodoxos, proscritos y marginados, Madrid, Siglo XXI, 2006, pp. 255-283.

BAZÁn, Iñaki, Los herejes de Durango y la búsqueda de la Edad del Espíritu Santo en el siglo XV. Durango, Museo de Arte e Historia de Durango, 2007.

BAZÁN, Ińaki, «María San Juan (Guernica, 1489-1490), una mujer acosada para forzar una relación sexual no consentida», en M. J. Fuente y R. Morán (eds.), Raíces profundas. La violencia contra las mujeres (Antigüedad y Edad Media), Madrid, Polifemo, 2011, pp. 277-304.

BAZÁN, Ińaki, «La pervivencia de la venganza privada junto al ius puniendi real en los casos de contumacia, piratería y uxoricidio honoris causa en la Corona de Castilla (siglos XIII al XV)», en C. Gauvard \& A. Zorzi (eds.), La vengance en Europe XIII'-XVIII siècles, Paris, Publications de la Sorbonne, 2015, pp. 209-226.

BAZÁn, Iñaki, «The formation of the basque institutional framework at the end of the Middle Ages and its historical legacy", en Peoples, identities and regions. Spain, Russia and the challenges of the multi-ethnic state, Moscow, Russian Academy of Sciences, 2015, pp. 79-92.

BAZÁn, Ińaki, «El pecado y el delito de adulterio en la Castilla medieval. Transgresiones del modelo de sexualidad conyugal y su castigo", en Arte y sexualidad en los siglos del románico: imágenes y contextos, Aguilar de Campoo, Fundación Santa María la Real del Patrimonio Histórico, 2018, pp. 11-51.

BAzÁN, Iñaki (ed.), La persecución de la delincuencia en despoblado en la Edad Media: las hermandades concejiles y otras instituciones afines, núm. monográfico de Clio \& Crimen. Revista del centro de Historia del Crimen de Durango, n. 3 (2006), pp. 6-529.

Bercé, Yves-Marie, «Aspects de la criminalité au Xvir ${ }^{e}$ siècle». Revue Historique, n. ${ }^{\circ} 239$ (1968), pp. 33-42.

Berraondo Piudo, Mikel, La violencia interpersonal en la Navarra moderna (siglos XVI-XVII). Pamplona, Universidad de Navarra, 2012 (tesis doctoral). 
Billacois, François, «Pour une enquête sur la criminalité dans la France d'Ancien Régime». Annales. Economies, sociétés, civilisations, n. ${ }^{\circ} 2$ (1967), pp. 340-349.

Botelet, Bernadette, «Etude par sondage de la criminalité dans le bailliage du Pont-de-l'Arche (xvire-Xvirie siècles)». Annales de Normandie, n. 4 (1962) pp. 235-262.

Bourdieu, Pierre, Razones prácticas sobre la teoría de la acción. Barcelona, Anagrama, 1997 (1994).

Brissaud, Yves-Bernard, «L'infanticide à la fin du Moyen Âge, ses motivations psychologiques et sa répression». Revue Historique de Droit Français et Étranger, n. 95 (1972), pp. 229-256.

Carter Wood, J., "Criminal violence in modern Britain». History Compass, n. ${ }^{\circ}$ 4-1 (2006), pp. 77-90.

Castan, Yves, Honnêteté et relations sociales en Languedoc 1715-1780. Paris, Plon, 1974.

Castan, Nicole, «Bilan de l'apport de la recherche historique à la connaisance de la criminalité et de la justice pénale», en La recherche historique sur la criminalité et la justice pénale, Strasbourg, Conseil d'Europe, 1984, pp. 9-26.

Castiglione, Baldassare, El cortesano. Madrid, Alianza Editorial, 2008.

Chiffoleau, Jacques, «La violence au quotidien. Avignon au Xiv siècle d'après les registres de la Cour temporelle». Mélanges de l'Ecole Française de Rome. Moyen-Âge, Temps modernes, t. 92, n. 2 (1980), p. 325-371.

Chiffoleau, Jacques, Les justices du pape. délinquance et criminalité dans la région d'Avignon au XIVè siècle. Paris, Publications de la Sorbonne, 1984.

Chaunu, Pierre, «Histoire quantitative ou histoire sérielle». Cahiers Vilfredo Pareto, t. III (1964), pp. $165-176$

Chaunu, Pierre, «Les dépassements de l'histoire quantitative: retrospective et perspective». Mélanges de la Casa de Velázques, t. 8 (1972), pp. 647-685.

Chaunu, Pierre, «Un nouveau champ pour l'histoire sérielle, le quantitatif au troisième niveau», en Mélanges en l'honneur de Fernand Braudel. T. I. Histoire économique du monde méditerranéen 1450-1650, Toulouse, Privat, 1972, pp. 105-127.

Collard, Frank, Le crime de poison au Moyen Âge. Paris, PUF, 2003.

Contreras, Jaime, El Santo Oficio de la Inquisición en Galicia. Madrid, Akal, 1982.

Córdoba de la Llave, Ricardo, «El homicidio en Andalucía a fines de la Edad Media. Primera parte. Estudio». Clio \& Crimen. Revista del Centro de Historia del Crimen de Durango, n. 2 (2005), pp. 278-504; y «Segunda parte. Documentos», pp. 506-707. Posteriormente publicado como libro por la Universidad de Granada en 2017 con el mismo título: El homicidio en Andalucía a fines de la Edad Media.

Córdoba de la Llave, Ricardo, «Violencia, delincuencia e inestabilidad social en la Castilla bajomedieval: los límites de la documentación", en L'Espai del mal, Lleida, Pagès Editors, 2005, pp. 319-338.

CóRdoba de la Llave, Ricardo, Mujer, marginación y violencia entre la Edad Media y los Tiempos Modernos. Córdoba, Universidad de Córdoba, 2006.

Córdoba de la Llave, Ricardo, «Marginación social y criminalización de las conductas». Medievalismo: Boletín de la Sociedad Española de Estudios Medievales, n. ${ }^{\circ}$ 13-14 (2004), pp. 293-322.

Deyon, Pierre, «Délinquance et repression dans le Nord de la France au Xvirie siècle». Bulletin de la Société d'Histoire Moderne, n. ${ }^{\circ}$ 20, 1972, pp. 10-15. 
Díaz de Durana, José Ramón, «Violencia, disentimiento y conflicto en la sociedad vasca durante la Baja Edad Media: la lucha de bandos, estado de la cuestión de un problema historiográfico», en Violencia y conflictividad en la sociedad de la España bajomedieval, Zaragoza, Universidad de Zaragoza, 1994, pp. 27-58.

Díaz de Durana, José Ramón (coord.), La lucha de bandos en el País Vasco: de los Parientes Mayores a la hidalguía universal. Guipúzcoa, de los bandos a la provincia (siglos XIV a XVI). Bilbao, Universidad del País Vasco, 1998.

Dinges, Martin, «Formenwandel der Gewalt in der Neuzeit. Zur Kritik der Zivilisations theorie von Norbert Elias», en R.P. Sieferle \& H. Breuninger (eds.), Kulturen der Gewalt. Ritualisierung und Symbolisierung von Gewalt in der Geschichte, Frankfurt am Main, Campus, 1998, pp. 171-194.

Donald, Kelley, «El giro cultural en la investigación histórica», en I. OlábarRi \& F. CASPISTEgui (coords.), La «nueva» Historia cultural, la influencia del postestructuralismo y el auge de la interdisciplinariedad, Madrid, Universidad Complutense, 1996, pp. 35-48.

Dubert, Isidro, Historia de la familia en Galicia durante la Edad Moderna, 1550-1830. A Coruña, Ediciós do Castro, 1992.

Durkheim, Emile, Las reglas del método sociológico. México, Fondo de Cultura Económica, 1986 (1895).

EIsner, Manuel, «Modernization, self-control and lethal violence. The long-term dynamics of European homicide, rates in theoretical perspective». The British Journal of Criminology, n. ${ }^{\circ} 41$ (2001), pp. 618-638.

EISNER, Manuel, «Long-tern historical trends in violent crime». Crime and Justice. A Review of Research, n. ${ }^{\circ} 30$ (2003), pp. 83-142.

Elias, Norbert, El proceso de la civilización. Investigaciones sociogenéticas y psicogenéticas. México, Fondo de Cultura Económica, 1988 (1939).

FARge, Arlette, La atracción del archivo. Valencia, Edicions Alfons el Magnànim, 1991 (1989).

FINCH, A.J., «The nature of violence in the Middle Ages: an alternative perspective». Historical Research, vol. Lxx, n. 173 (1997), pp. 249-268.

Foucault, Michel, Vigilary castigar. Nacimiento de la prisión. Buenos Aires, Siglo XXI, 2002 (1975).

García Herrero, M. ${ }^{a}$ del Carmen, "Árbitras, arbitradoras y amigables componedoras en la Baja Edad Media aragonesa», en M. ${ }^{a}$ del C. García Herrero, Del nacer y el vivir. Fragmentos para una historia de la vida en la Baja Edad Media, Zaragoza, Institución Fernando el Católico, 2005, pp. 353-383.

García Herrero, M. ${ }^{a}$ del Carmen, «La marital corrección. Un tipo de violencia aceptado en la Baja Edad Media». Clio \& Crimen. Revista del Centro de Historia del Crimen de Durango, n. 5 (2008), pp. 39-71.

García Herrero, M. ${ }^{a}$ del Carmen, «Vulnerables y temidos: los varones jóvenes como grupo de riesgo para el pecado y el delito en la Baja Edad Media», en M. ${ }^{a}$ del C. García Herrero, Los jóvenes en la Baja Edad Media. Estudios y testimonios, Zaragoza, Institución Fernando el Católico, 2018; pp. 113-148.

Garnot, Benoît, «Délits et châtiments en Anjou au xvirie siècle». Annales de Bretagne et des Pays de l'Ouest, n. ${ }^{\circ}$ 88-3 (1981), pp. 283-304. 
Garnot, Benoît, «L'Historiographie de la criminalité pour la periode moderne», en B. Garnot (dir.), Histoire et criminalité de l'Antiquite au XXe siècle. Nouvelles aproches, Dijon-Quetigny, Université de Bourgogne, 1992, pp. 25-29.

Garnot, Benoît, La justice en France de l'an mil à 1914. Paris, Nathan, 1993.

Garnot, Benoît, «Justice, infrajustice, parajustice et extra justice dans la France d'Ancien Régimen». Crime, Histoire \& Sociétés / Crime, History \& Societies, vol. 4, n. ${ }^{\circ} 1$ (2000), pp. 103-120.

Garnot, Benoît, (dir.), L'Infrajudiciaire du Moyen Âge à l'Époque Contemporaine. Dijon, Éditions Universitaires de Dijon, 1996.

Gauvard, Claude, "De grace especial». Crime, État et société en France à la fin du Moyen Âge. Paris, Publications de la Sorbonne, 1991, 2 vols.

Gauvard, Claude, «Violence citadine et réseaux de solidarité. L'example français au XIV et Xve siècles». Annales ESC, n. ${ }^{\circ} 48$ (1993), pp. 1119-1121.

Gauvard, Claude, «Les sources de la fin du Moyen Âge peuvent-elles permettre une aproche statisque du crime?», en P. Contamine \& T. Dufour \& B. Schenerb (éds.), Commerce, finances et société (XI-XVI). Menlanges Henri Dubois, Paris, Université de Paris-Sorbonne, 1993, pp. 469-488.

Gauvard, Claude, "Conclusion», en Le règlement des conflits au Moyen-Âge, Paris, Publications de la Sorbonne, 2001, pp. 373-374.

Gauvard, Claude \& ZorZI, Andrea (dirs.), La vengance en Europe, XIIe-XVIII siècle. Paris, Publications de la Sorbonne, 2015.

Geremex, Bronislaw, Les mariginaux parisiens aux XIVe et XVe siècles. Paris, Flammarion, 1976.

Geremer, Bronislaw, La piedad y la horca. Historia de la miseria y de la caridad en Europa. Madrid, Alianza Editorial, 1989 (1. ${ }^{a}$ ed. francesa 1986).

Geremex, Bronislaw, La estirpe de Cain. La imagen de los vagabundos y de los pobres en la literatura europea de los siglos XV al XVII. Madrid, Mondadori, 1991.

GinzBurg, Carlo, El queso y los gusanos. El cosmos, según un molinero del siglo XVI. Barcelona, Muchnik, 1999 (1976).

Given, James B., Society and homicide in Thirteenth century England. Stanford, Stanford University Press, 1977.

Grendi, Edoardo, «Microanalisi e storia sociale». Quaderni Storici, n. ${ }^{\circ} 35$ (1977), pp. 506-520.

GURR Ted R., «Historical trends in violent crime: a critical review of the evidence». Crime and Justice: An Annual Review of Research, III (1981), pp. 295-353.

Gutton, Jean Pierre, La société et les pauvres en Europe, XVIe-XVIII siècles. Paris, PUF, 1974.

Hanawalt, Barbara A., "Economic influences on the pattern of crime in England, 1300-1348». The American Journal of Legal History, vol. 18, n. ${ }^{\circ} 4$ (1974), pp. 281-297.

Hanawalt, Barbara A., «Violent death in Fourteenth and Early Fifteenth century England». Comparative Studies in Society and History, vol. 18, n. 3 (1976), pp. 297-320.

Hanawalt, Barbara A., Crime and conflict in English communities, 1300-1348. Cambridge, Harvard University Press, 1979.

Heras, José Luis de las, La justicia penal de los Austrias en la Corona de Castilla. Salamanca, Universidad de Salamanca, 1994. 
HäRTER, Karl, «Disciplinamento sociale e ordinanze di polizia nella prima età moderna», en P. PRODI (ed.), Disciplina dell'anima, disciplina del corpo e disciplina della societè tra medioevo ed età moderna, Bologna, Il Mulino, 1994, pp. 635-658.

Henningsen, Gustav, «El "Banco de datos” del Santo Oficio. Las relaciones de causas de la Inquisición española (1500-1700)». Boletín de la Real Academia de la Historia, n. ${ }^{\circ} 74$ (1977), pp. 547-570.

Izquierdo Benito, Ricardo, Un espacio desordenado. Toledo a fines de la Edad Media. Toledo, Universidad de Castilla-La Mancha, 1996.

ЈАСОВ, Robert, Images de la justice. Essai sur l'iconographie judiciaire du Moyen Âge à l'Âge classique. Paris, Le Léopard d'Or, 1994.

Johansen, Jens C. \& Stevnsborg, Henrik, «Hasard ou myopie. Réflexions autor de deux théories de l'histoire du droit». Annales ESC, n. ${ }^{\circ} 41-3$ (1986), pp. 614-617.

Kagan, Richard L., Pleitos y pleiteantes en Castilla, 1500-1700. Valladolid, Junta de Castilla y León, 1991.

Lebrun François, Les hommes et la mort en Anjou au $17^{e}$ et $18^{e}$ siècles. Essai de démographie et de psychologie historiques. Paris-La Haye, Mouton, 1971.

Lenman, Bruce \& Parker, Geoffrey, «The State, the Community and the modern law in Early Modern Europe», en V.A.C. Gattrel, B. Lenman \& G. Parker (eds.), Crime and the law. The social history of crime in Wester Europe since 1500, London, Europa Publications, 1980, pp. 11-48.

Le Roy Ladurie, Emanuelle, «La décroissance du crime au XVIII ${ }^{e}$ siècle, bilan d'historiens». Contrepoint, n. 9 (1973), pp. 227-233.

Le Roy Ladurie, Emanuelle, Montaillou, aldea occitana, de 1294 a 1324. Madrid, Taurus, 1988 (1975).

Lis, Catharina \& Soly, Hugo, Poverty and capitalism in pre-industrial Europe. Brighton, The Harvester Press, 1979.

López Alonso, Carmen, La pobreza en la España medieval: estudio histórico-social. Madrid, Ministerio de Trabajo y Seguridad Social, 1986.

Lorcin, Marie Th., «Les paysans et la justice dans la región lyonnaise aux XIV et Xve siècles». Le Moyen Âge, t. 74 (1968), pp. 269-300.

Macfarlane, Alan, The justice and the Mare's Ale: Law and disorder in Seventeenth-Century England. New York, Cambridge University Press, 1981 (con la colaboración de Sarah Harrison).

Maddern, Philippa C., Violence and social order: East Anglia, 1422-1442. Oxford, Clarendon Press, 1992.

Maiza, Carlos, «La definición del concepto del honor. Su identidad como objeto de investigación histórica». Espacio, Tiempo y Forma. Historia Moderna, n. 8 (1995), pp. 191-209.

Mantecón, Tomás A., Conflictividad y disciplinamiento social en la Cantabria rural del Antiguo Régimen. Santander, Universidad de Cantabria y Fundación Marcelino Botín, 1997.

Mantecón, Tomás A., «El peso de la infrajudicialidad en el control del crimen durante la Edad Moderna». Estudis. Revista de Historia Moderna, n. 28 (2002), pp. 43-76.

Mantecón, Tomás A., "Formas de disciplinamiento social, perspectivas históricas». Revista de Historia Social y de las Mentalidades, vol. 14, n. ${ }^{\circ}$ (2010), pp. 263-295. 
Martín Miguel, María Ángeles, «Las relaciones extramaritales: documentos de estupro, desistimiento de esponsales y reconocimiento de hijos ilegítimos», en M. ${ }^{a} \mathrm{R}$. Porres (coord.), Aproximación metodológica a los protocolos notariales de Álava (Edad Moderna), Bilbao, Universidad del País Vasco, 1996, pp. 213-220.

Mendoza, Juan Miguel, Violencia y delincuencia en el Campo de Calatrava a fines de la Edad Media. Ciudad Real, Instituto de Estudios Manchegos, 1992.

Mendoza, Juan Miguel, «La delincuencia a fines de la Edad Media. Un balance historiográfico». Historia. Instituciones. Documentos, n. 20 (1993), pp. 231-260.

Mendoza, Juan Miguel, Delincuencia y represión en la Castilla bajomedieval: los territorios castellanomanchegos, Granada, Grupo Editorial Universitario, 1999.

Mendoza, Juan Miguel, «Sobre la delincuencia femenina en Castilla a fines de la Edad Media», en R. Córdoba de la Llave (coord.), Mujer, marginación y violencia entre la Edad Media y los tiempos modernos, Córdoba, Servicio de Publicaciones de la Universidad de Córdoba, 2006, pp. 75-126.

Monknonen, Eric, «New standards for historical homicide research». Crime, Histoire \& Sociétés / Crime, History \& Societies, vol. 5, n. ${ }^{\circ} 2$ (2001), pp. 5-26.

Moreta, Salustiano, Malhechores-feudales: violencia, antagonismo y alianzas de clases en Castilla, siglos XIII-XIV. Madrid, Cátedra, 1978.

Morín, Alejandro, Pecado y delito en la Edad Media: estudio de una relación a partir de la obra jurídica de Alfonso el Sabio. Córdoba, Del Copista, 2009.

Mucchielli, Laurent \& Spierenburg, Pieter (dirs.), Histoire de l'homicide en Europe, de la fin du Moyen Âge à nos jours. Paris, La Découvert, 2009.

Muchembled, Robert, «Les jeunes, les jeux et la violence en Artois au xve siècle», en P. AriÈs \& J.-C. Margolin (eds.), Les jeux à la Renaissance, Paris, Vrin, 1982, pp. 563-579.

Muchembled, Robert, «Anthropologie de la violence dans la France moderne (xve-xvirie siècle)». Revue de Synthèse, IV siècle, . $^{\circ} 1$ (1987), pp. 31-55.

Muchembled, Robert, L'invention de l'homme moderne. Sensibilités, moeurs et comportements collectifs sous l'Ancien Régime. Fayard, Paris, 1988.

Muchembled, Robert, La violence au village. Sociabilité et comportaments populaires en Artois de Xve au XVII siècle. Turnhout, Brepols, 1989.

Muchembled, Robert, Una historia de la violencia. Del final de la Edad Media a la actualidad. Paidós, Madrid, 2010 (2008).

Narbona Vizcaíno, Rafael, Malhechores, violencia y justicia ciudadana en Valencia bajomedieval (1369-1399). Valencia, Ayuntamiento de Valencia, 1990.

Nirenberg, David, Communities of violence. Persecution of minorities in the Middle Age. Princeton University Press, 1996.

Orella Unzúe, José Luis, «Las Hermandades Vascas en el marco de la Santa Hermandad como instrumento de control de delitos e impartición de penas», en I. BAZÁn (ed.), Clio \& Crimen, n. ${ }^{\circ} 3$ (2006) (Monográfico La persecución de la delincuencia en despoblado en la Edad Media: las hermandades concejiles y otras instituciones afines), pp. 68-133.

Österberg, Eva, «Violence Among Peasants Comparative on the 16th and 17th Century Sweden», en G. Rystad (ed.), Europe and Scandinavia. Aspects of the process of integration in the 17th century, Lund, Scandinavian University Books, 1983, pp. 257-275. 
Österberg, Eva, «Gender, class, and the courts: Scandinavia», en C. EmSley \& L.A. KNAFla (eds.), Crime history and histories of crime. Studies in the historiography of crime and criminal justice in Modern History, Wetport-London, Greenwood Press, 1996, pp. 47-65.

Pavan, Elisabeth, «Violence, société et pouvoir à Venise (xIv-xv siècles)». Mélanges de l'École Française de Rome, n. 96 (1984), pp. 903-936.

Pérez García, Pablo, «Una reflexión en torno a la historia de la criminalidad». Revista d'Historia Medieval, n. ${ }^{\circ} 1$ (1990), pp. 11-37.

Porret, Michelle (ed.), L'Impossible prison. Recherches sur le système pénitentiaire au XIXe siècle. Paris, Seuil, 1980.

Puppi, Lionello, Les supplices dans l'art. Cérémonial des exécutions capitales et iconographie du martyre dans l'art européen du XII a u XIXe siècle. Paris, Larousse, 1991 (Milán 1990).

Ramos VÁzquez, Isabel, «La represión de los delitos atroces en el derecho castellano de la Edad Moderna». Revista de Estudios histórico-jurídicos, n. 26 (2004), pp. 255-299.

ReinhardT, Wolfgang, «Disciplinamento sociale, confessionalizazione, modernizzazione. Un discorso storiografico", en C. Penuti (ed.), Disciplina dell'anima, disciplina del corpo e disciplina della societè tra medievo ed età moderna, Bologna, 1994, pp. 101-123.

Reyes Echeandía, Alfonso, Criminología. Colombia, Temis, 1987 (8. ${ }^{a}$ ed.).

Roodenburg, Herman \& Spierenburg, Pieter (eds.), Social control in Europe. Vol. 1, 1500-1800. Columbus, The Ohio State University Press, 2004.

Rodríguez Barral, Paulino, La justicia del más allá. Iconografía en la Corona de Aragón en la Baja Edad Media. València, Universitat de València, 2007.

Rodríguez GonzÁLez, Alfredo, «El infanticidio en la España moderna: entre la realidad y el discurso jurídico y moral». Tiempos Modernos, n. ${ }^{\circ} 36$ (2018/1), pp. 280-301.

Rodríguez Manzanera, Luis, Criminología. México, Editorial Porrúa, 1981 (1979).

Roodenburg, Herman, "The "hand of friendship"», en J. Bremmer \& H. Roodenburg (eds.), Cultural history of gesture: from antiquity to the present day, Cambridge, Polity Press, 1991, pp. 152-189.

Rousseaux, Xavier, "Crime, Justice and Society in Medieval and Early Modern Times Thirty Years of Crime and Criminal Justice History. A tribute to Herman Diederiks». Crime, Histoire \& Sociétés / Crime, History \& Societies, vol. 1, n. ${ }^{\circ} 1$ (1997), pp. 87-118.

Rousseaux, Xavier, «Historiographie du crime et de la justice criminelle dans l'espace français (19902005). Partie I: du Moyen-Âge à la fin de l’Ancien Régime». Crime, Histoire \& Sociétés / Crime, History \& Societies, vol. 10, n. ${ }^{\circ} 1$ (2006), pp. 123-158.

Rousseaux, Xavier, Dauven Bernard \& Musin Aude, "Civilisation des moeurs et/ou disciplinarisation sociale? Les sociétés urbaines face à la violence en Europe (1300-1800)», en L. Mucchielli \& P. Spierenburg (dirs.), Histoire de l'homicide en Europe. De la fin du Moyen-Age à nos jours, Paris, La Découverte, 2009, pp. 275-323.

Ruiz Gallegos, Yésica, Aproximación al estudio del juicio final y del juicio del alma en la Corona de Castilla en la Baja Edad Media. Bilbao, Universidad del País Vasco, 2008.

Sabaté, Flocel, "Femmes et violencia dans la Catalogne du Xiv siècle». Annales du Midi. Revue de la France méridionale, t. 106, n. ${ }^{\circ} 207$ (1994), pp. 277-316.

Sabaté, Flocel, «Orden y desorden. La violencia en la cotidianidad bajomedieval catalana». Aragón en la Edad Media, n. ${ }^{\circ}$ 14-15, fascículo 2 (1999), pp. 1389-1408. 
SÁnchez Benito, José M.a, Santa Hermandad Vieja de Toledo, Talavera y Ciudad Real (siglos XIII-XV). Toledo, Caja de Ahorros Provincial de Toledo, 1987.

SÁnchez Benito, José M. a , "Criminalidad en época de los Reyes Católicos. Delincuentes perseguidos por la Hermandad", en Estudios de Historia Medieval en homenaje a Luis Suárez Fernández, Valladolid, Universidad de Valladolid, 1991, pp. 411-424.

Schilling, Heinz, «El disciplinamiento social en la Edad Moderna: propuesta de indagación interdisciplinar y comparativa», en J.I. Fortéa, J.E. Gelabert \& T.A. Mantecón (eds.), Furor et rabies. Violencia, conflicto y marginación en la Edad Moderna, Santander, Universidad de Cantabria, 2002, pp. 17-45.

Schwerhoff, Gerd, «Zivilisationsprozess und Geschichtswissenschaft. Norbert Elias Forschungsparadigma in historischer Sicht». Historische Zeitschrift, n. ${ }^{\circ} 266$ (1998), pp. 561-605.

SCHWERHOFF, Gerd, «La storia della criminalità nel tardo medioevo e nella prima età moderna. Il "ritardo" di un settore della ricerca tedesca». Annali dell'Istituto Storico italo-germanico in Trento, n. 24 (1999), pp. 573-630.

Schwerhoff, Gerd, "Criminalized violence and the process of civilisation: a reappraisal». Crime, Histoire \& Sociétés / Crime, History \& Societies, vol. 6, n. ${ }^{\circ} 2$ (2002), pp. 103-126.

Schuster Peter, Der gelobte Frieden. Täter, Opfer und Herrschaft im spätmittelalterlichen Konstanz. Konstanz, Universitätsverlag, 1995.

SEgUra URRA, Félix, «Raíces historiográficas y actualidad de la historia de la justicia y el crimen en la Baja Edad Media». Anuario de Historia del Derecho Español, t. 73 (2003), pp. 577-678.

Segura Urra, Félix, «La historia de la delincuencia en la España medieval (1998-2008)». Medievalismo, n. ${ }^{\circ} 18$ (2008), pp. 273-338.

Sharpe, James A., Crime in Early Modern England 1550-1750. London, Longman, 1984.

Sharpe, James A., «The history of violence in England: some observations». Past \& Present, n. ${ }^{\circ} 108$ (1985), pp. 206-215.

Sieferle, Rolf Peter \& Breuninger, Helga (eds.), Kulturen der Gewalt. Ritualisierung und Sym bolisierung von Gewalt in der Geschichte. Frankfurt/New York, Campus Verlag, 1998.

Spirenburg, Pieter, «Faces of violence. Homicide trends and cultural meanings: Amsterdam, 14311816». Journal of Social History, n. 27 (1994), pp. 701-716.

Spirenburg, Pieter, «Long-tern trends in homicide: theretical reflections and Dutch evidence, fifteenth to twentieth centuries», en E.A. Johnson \& E.H. Monkкonen (dirs.), The Civilization of crime. Violence in town and country since Middle Ages, Urbana-Chicago, University of Illinois Press, 1996, pp. 63-105.

Spirenburg, Pieter, «Violence and the civilizing process: does it work?». Crime, Histoire \& Sociétés / Crime, History \& Societies, vol. 5, n. ${ }^{\circ}$ (2001), pp. 87-105.

Spirenburg, Pieter, «Social control and History: an introduction», en H. Roodenburg \& P. SpieRenburg (eds.), Social control in Europe. Vol. 1, 1500-1800, Columbus: Ohio State University Press, 2004, pp. 1-24.

Spirenburg, Pieter, «L'Homicide et la loi en la République des Pays-Bas du Nord: un pays pacifique?», en L. Mucchielli \& P. Spierenburg (dirs.), Histoire de l'homicide en Europe. De la fin du Moyen Âge à nos jours, Paris, La Découverte, 2009, pp. 53-83.

Soman, Alfred, «L'infrajustice à Paris après les archives notariales». Histoire, Économie et Société, n. 3 (1982), pp. 369-376. 
Stone, Lawrence, «Interpersonal violence in English society 1300-1980». Past \& Present, n. ${ }^{\circ} 101$ (1983), pp. 22-33.

Toureille, Valérie, Crime et châtiment au Moyen Âge, ve-Xve siècle. Paris, Seuil, 2013.

Trinidad Fernández, Pedro, La defensa de la sociedad: cárcel y delincuencia en España (siglos XVIIIXX). Madrid, Alianza, 1991.

VILAR, Pierre, «Pour une meilleure compréhension entre économistes et historiens. Histoire quantitative ou économique rétrospective?». Revue Historique, t. cCXxiII (1965), pp. 293-312.

Villacorta, M. ${ }^{a}$ Consuelo, Edición critica del Libro de las buenas andanças e fortunas que fizo Lope Garçía de Salazar. Bilbao, Universidad del País Vasco, 2005.

VIŃa BRITo, Ana, «La "carta de perdón de cuernos" en la documentación notarial canaria del siglo XVI». Revista de Historia Canaria, n. ${ }^{\circ} 20$ (2005), pp. 263-272.

Vovelle, Michel, Piété baroque et déchristianisation en Provence au XVIII siècle. Les attitudes devant la mort d'après les clause des testaments. Paris, Plon, 1973.

Weber, Max, Economía y sociedad. Esbozo de sociología comprensiva. Madrid, Fondo de Cultura Económica, 2002 (1922).

WeIsser, Michael R., Criminalita e repressione nell'Europa Moderna. Bologna, Il Mulino, 1989 (1979). 